Supporting Information for:

\title{
Antibody Probes of Module 1 of the 6-Deoxyerythronolide B Synthase Reveal an Extended Conformation During Ketoreduction
}

Dillon P. Cogan ${ }^{1}$, Xiuyuan $\mathrm{Li}^{1}$, Natalia Sevillano ${ }^{2}$, Irimpan I. Mathews ${ }^{3}$, Tsutomu Matsui ${ }^{3}$, Charles S. Craik ${ }^{2}$, and Chaitan Khosla ${ }^{1,4,5^{*}}$

${ }^{1}$ Departments of Chemistry, ${ }^{4}$ Chemical Engineering, and ${ }^{5}$ Stanford ChEM-H, Stanford University, Stanford, California 94305, United States

${ }^{2}$ Department of Pharmaceutical Chemistry, University of California San Francisco, San Francisco, California 94158, United States

${ }^{3}$ Stanford Synchrotron Radiation Lightsource, SLAC National Accelerator Laboratory, Stanford University, Menlo Park, California 94025, United States

*Corresponding author: khosla@stanford.edu

\section{Table of Contents}

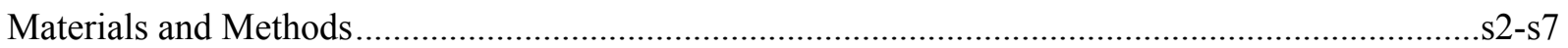

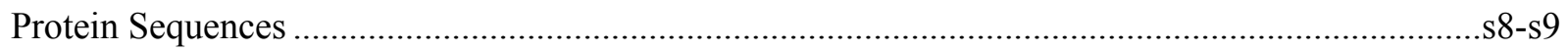

Supporting Figures

Figure $\mathrm{S} 1: \mathrm{F}_{\mathrm{ab}}$ binding specificity for DEBS module 1/KR1 by ELISA ....................................... 10

Figure S2: Effect of T1D and NADPH concentration on KR1-mediated reduction of T1D .......s11

Figure S3: Inhibition of KR1-mediated reduction of T1D by 1D10 ….................................... 12

Figure S4: NADPH and 1D10 dependence on KR1-mediated reduction of T1D.......................s13

Figure S5: Superposition of KR1-NADP ${ }^{+}$onto KR1- $\mathrm{F}_{\mathrm{ab}}$ structures ............................................. 14

Figure S6: Superposition of KR1- $\mathrm{F}_{\mathrm{ab}}$ structures onto the arched and extended models of an assembly-line PKS module ................................................................................... 15

Figure S7: Purification and size-exclusion chromatography analysis of M3/1+TE ....................s16

Figure S8: Enzyme inactivity of M3/1+TE in a DEBS bimodule .............................................. 17

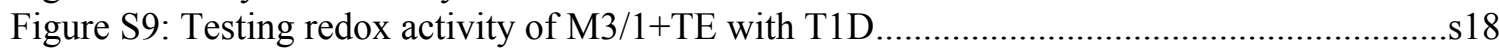

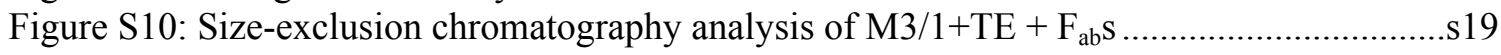

Figure S11: Two models of an arched PKS module featuring a TE domain .............................s20

Figure S12: Small-angle X-ray scattering analysis of $\mathrm{F}_{\mathrm{ab}}-\mathrm{M} 3 / 1+\mathrm{TE}$ compared to simulated curves of arched+TE model 2 and the extended model .........................................s2 1

Figure S13: Small-angle X-ray scattering analysis of $F_{a b}-M 3 / 1+T E$ compared to simulated curves of the arched model (no TE) and the extended model .................................s22

Figure S14: Ab initio SAXS envelopes calculated from the $\mathrm{F}_{\mathrm{ab}}-\mathrm{M} 3 / 1+\mathrm{TE}$ data ........................... 23 Supporting Tables

Table S1: Crystallographic data collection and refinement statistics.......................................s24

Table S2: SEC-SAXS data collection and processing parameters ............................................... 25

Table S3: Summary of SAXS curve fitting data ...................................................................... 26

Table S4: Summary of SAXS curve fitting data for singly $\mathrm{F}_{\mathrm{ab}}$-bound modules .........................s2

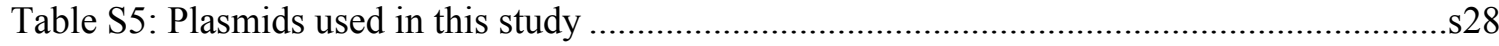

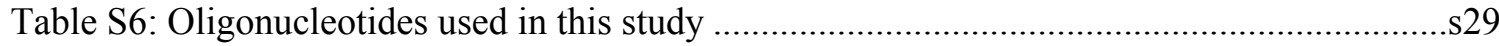

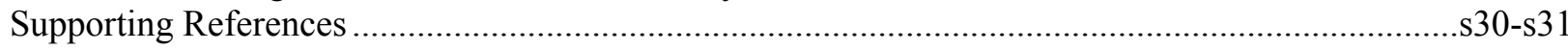




\section{Materials and Methods}

\section{Materials}

All chemicals, purification resins, plasmid extraction kits, and bacterial growth media were purchased from MilliPore Sigma or Thermo Fisher Scientific. Isopropyl $\beta$-D-1-thiogalactopyranoside (IPTG) and all antibiotics were purchased from Gold Biotechnology. Enzymes for PCR and Gibson Assembly were purchased from Takara Bio USA, Inc. (Mountain View, CA). Oligonucleotides and DNA sequencing data were procured from Elim Biopharmaceutical Inc (Hayward, CA).

Construction of 6-deoxyerythronolide B synthase (DEBS) and auxiliary enzyme overexpression plasmids See Table S5 for a list of plasmids used in this study and their origins. Plasmid pTED23 was constructed by PCR amplifying the following (see Supporting Table S6 for primer sequences): (1) pRSG34-derived fragment from the $\mathrm{Amp}^{\mathrm{R}}$ gene (5') to Tyr921 of M3 (3'); (2) pBL13-derived fragment containing the AT3/KR1 interface (5') and ACP1/TE interface (3') (i.e., KR1-ACP1 M1 fragment from Arg1425Gly1984); (3) pRSG34-derived fragment including the TE-domain from Ser2895 (5') to the Amp ${ }^{\mathrm{R}}$ gene (3'). The three fragments were circularized in a Gibson Assembly reaction ${ }^{1,2}$, the contents of which were used to transform E. coli DH5 $\alpha$. Successful assembly of the plasmid was verified by Elim Biopharmaceutical Inc. sequencing services.

\section{Expression and purification of DEBS proteins}

Expression plasmids (Table S5) were used to transform E. coli BL21(DE3) or BAP1 cells ${ }^{3}$. Single transformant colonies were used to inoculate $5 \mathrm{~mL}$ Luria-Bertani (LB) media supplemented with appropriate antibiotics $(100 \mathrm{mg} / \mathrm{L}$ carbenicillin disodium or $50 \mathrm{mg} / \mathrm{L}$ kanamycin monosulfate) for overnight growth at $37^{\circ} \mathrm{C}$ (Table S5). The next day, $2 \mathrm{~mL}$ of overnight seed culture were used to inoculate each liter of LB media containing appropriate antibiotics (4-8 L total) and grown further at $37{ }^{\circ} \mathrm{C}(220 \mathrm{rpm})$ until an optical density at $600 \mathrm{~nm}\left(\mathrm{OD}_{600}\right)$ of $\sim 0.4-0.8$ was achieved. Brief cooling of cell culture flasks in an icebath (15-20 min) was followed by addition of $0.25 \mathrm{mM}$ IPTG and growth at $18{ }^{\circ} \mathrm{C}(220 \mathrm{rpm})$ for $18-20 \mathrm{~h}$. Cells were harvested by centrifugation at 5,000 relative centrifugal force (RCF) at $4{ }^{\circ} \mathrm{C}$ for 20 min using an Avanti-JE Beckman centrifuge and resuspended in $5 \mathrm{~mL}$ of lysis buffer $(10 \mathrm{mM}$ imidazole, $450 \mathrm{mM}$ $\mathrm{NaCl}, 20 \%$ glycerol, $50 \mathrm{mM} \mathrm{Na}_{2} \mathrm{HPO}_{4}, \mathrm{pH} 7.8$ ) per liter of cell culture. Lysis of cells was accomplished by sonication and cell lysate was cleared by centrifugation at 25,000 RCF at $4{ }^{\circ} \mathrm{C}$ for $1 \mathrm{~h}$ using an Avanti-JE Beckman centrifuge. Clarified lysate was applied to Ni-NTA resin (Thermo Fisher Scientific; $1 \mathrm{~mL}$ resin per liter of cell culture) pre-equilibrated in wash buffer $(50 \mathrm{mM}$ imidazole, $300 \mathrm{mM} \mathrm{NaCl}, 10 \%$ glycerol, $50 \mathrm{mM} \mathrm{Na}_{2} \mathrm{HPO}_{4}, \mathrm{pH} 7.8$ ) and incubated as a suspension for $20 \mathrm{~min}$ in a Kimble-Kontes Flex column before eluting by gravity. The resin was washed with $80 \mathrm{~mL}$ of wash buffer, then bound proteins were eluted with $50 \mathrm{~mL}$ of elution buffer ( $500 \mathrm{mM}$ imidazole, $40 \mathrm{mM} \mathrm{NaCl}, 10 \%$ glycerol, $50 \mathrm{mM} \mathrm{Na}_{2} \mathrm{HPO}_{4}, \mathrm{pH}$ 7.6). The entire eluant was injected onto a $5 \mathrm{~mL}$ HiTrap Q HP anion exchange column (GE Healthcare) equilibrated with buffer A $\left(50 \mathrm{mM} \mathrm{NaCl}, 10 \%\right.$ glycerol, $50 \mathrm{mM} \mathrm{Na}_{2} \mathrm{HPO}_{4}, \mathrm{pH}$ 7.6) using an ÄKTA Pure protein purification FPLC system (GE Healthcare). The column was washed with $50 \mathrm{~mL}$ of buffer A before implementing a 0-60\% linear gradient of increasing buffer $\mathrm{B}\left(1 \mathrm{M} \mathrm{NaCl}, 10 \%\right.$ glycerol, $50 \mathrm{mM} \mathrm{Na}_{2} \mathrm{HPO}_{4}$, $\mathrm{pH}$ 7.6) while collecting $4 \mathrm{~mL}$ fractions. Eluted fractions were evaluated for purity by SDS-PAGE and pooled fractions were concentrated using Amicon Ultra Centrifugal Filters (Millipore Sigma), flash-frozen in liquid $\mathrm{N}_{2}$, then stored at $-80{ }^{\circ} \mathrm{C}$. Protein concentrations were determined prior to flash-freezing by the Bradford assay using bovine serum albumin (BSA) standards (Thermo Fisher Scientific). Unless otherwise stated, enzymes following this purification sequence were directly used in enzyme reactions.

\section{His $_{6}$-KRl tag removal and purification}

To $10 \mathrm{mg}$ of $\mathrm{His}_{6}$-KR1 from anion exchange purification (buffer composition is approx. $500 \mathrm{mM} \mathrm{NaCl}$, $10 \%$ glycerol, $50 \mathrm{mM} \mathrm{Na}_{2} \mathrm{HPO}_{4}$, $\mathrm{pH} 7.6$ based on $\mathrm{His}_{6}-\mathrm{KR} 1$ elution volume) was added $1 \mathrm{mM}$ DTT and 40 $\mathrm{U}$ of bovine thrombin. The proteolysis reaction $(1 \mathrm{~mL})$ was carried out overnight at $4{ }^{\circ} \mathrm{C}$ then quenched by 
manually injecting reaction contents onto a $1 \mathrm{~mL}$ HiTrap Benzamidine Fast Flow column (GE Healthcare). The column was manually washed via syringe injection with $20 \mathrm{~mL}$ of $150 \mathrm{mM} \mathrm{NaCl}, 1 \mathrm{mM}$ DTT, $10 \mathrm{mM}$ HEPES, pH 7.0. Protein was manually eluted via syringe injection with $20 \mathrm{~mL}$ of $1 \mathrm{M} \mathrm{NaCl}, 10 \%$ glycerol, $50 \mathrm{mM}$ HEPES, $\mathrm{pH} 7.6$ to afford $8.3 \mathrm{mg}$ ( $86 \%$ yield) of tag-free KR1, verified by SDS-PAGE. Tag-free KR1 was concentrated to $\leq 2 \mathrm{~mL}$ using Amicon Ultra Centrifugal Filters (Millipore Sigma) then further purified by size-exclusion chromatography (SEC, see below). All KR1 samples used in enzyme reactions or crystallography were in the tag-free, SEC-purified form (hereafter referred to as "KR1").

Expression and periplasmic extraction/purification of $F_{a b} S 1 B 2,1 D 10$, and $2 G 10$

$\mathrm{F}_{\mathrm{ab}}$ expression cells were generated by co-transforming $E$. coli $\mathrm{BL} 21(\mathrm{DE} 3)$ with a $\mathrm{F}_{\mathrm{ab}}$ expression plasmid (Table S5) and pACYCDuet-1 (Novagen), to included additional copies of LacI due to $\mathrm{F}_{\mathrm{ab}}$ toxicity. Transformant colonies grown at $30{ }^{\circ} \mathrm{C}$ on $2 x Y T$ medium plates supplemented with $2 \%$ glucose, $100 \mathrm{mg} / \mathrm{L}$ carbenicillin disodium, and $25 \mathrm{mg} / \mathrm{L}$ chloramphenicol were selected to inoculate $15 \mathrm{~mL}$ of similar media containing $0.1 \%$ glucose $\left(2 \times \mathrm{XT}_{-} \mathrm{F}_{\mathrm{ab}}\right.$ media) and grown at $30^{\circ} \mathrm{C}$ overnight. The next day, $2 \mathrm{~mL}$ of overnight seed culture were used to inoculate each liter of $2 \mathrm{xYT} \mathrm{F}_{\mathrm{ab}}$ media $(8 \mathrm{~L}$ total $)$ and grown further at $35^{\circ} \mathrm{C}(220$ $\mathrm{rpm}$ ) until an $\mathrm{OD}_{600}$ of $\sim 0.4-0.8$ was achieved. Brief cooling of cell culture flasks in an ice-bath (15 min) was followed by addition of $0.5 \mathrm{mM}$ IPTG and growth at $30^{\circ} \mathrm{C}(220 \mathrm{rpm})$ for 5-7 h. Cells were harvested by centrifugation at 5,000 RCF at $4{ }^{\circ} \mathrm{C}$ for 20 min using an Avanti-JE Beckman centrifuge and resuspended in $\sim 5 \mathrm{~mL}$ of HES buffer (0.5 mM EDTA, $500 \mathrm{mM}$ sucrose, $100 \mathrm{mM}$ HEPES, $\mathrm{pH} 7.8)$ per liter of cell culture, supplemented with $5 \%$ glycerol, then flash-frozen in liquid $\mathrm{N}_{2}$ and stored at $-80{ }^{\circ} \mathrm{C}$. Thawed cells were resuspended in $20 \mathrm{~mL}$ of HES buffer per liter of culture (including the resuspension volume) and stirred briskly for $2 \mathrm{~h}$ at $4{ }^{\circ} \mathrm{C}$. An equal volume of ice-cold water was added and stirring continued for another 1$2 \mathrm{~h}$. At the end of the osmotic shock, $10 \mathrm{mM}$ imidazole and $2.5 \mathrm{mM} \mathrm{MgCl}_{2}$ were added and stirring continued for another $5 \mathrm{~min}$ before clarifying the periplasmic extract by centrifugation at 25,000 RCF at 4 ${ }^{\circ} \mathrm{C}$ for $1 \mathrm{~h}$ using an Avanti-JE Beckman centrifuge. The supernatant was applied to Ni-NTA resin (Thermo Fisher Scientific; $1 \mathrm{~mL}$ resin per $50 \mathrm{~mL}$ of osmotic shock volume) pre-equilibrated in $\mathrm{F}_{\mathrm{ab}}$ wash buffer 1 $(250 \mathrm{mM} \mathrm{NaCl}, 50 \mathrm{mM}$ HEPES, pH 7.8) and stirred slowly in a $500 \mathrm{~mL}$ beaker for $1 \mathrm{~h}$. The slurry was added to a Kimble-Kontes Flex column and eluted by gravity. The resin was washed with $100 \mathrm{~mL}$ of $\mathrm{F}_{\mathrm{ab}}$ wash buffer 2 (20 mM imidazole, $500 \mathrm{mM} \mathrm{NaCl}, 50 \mathrm{mM}$ HEPES, $\mathrm{pH} 7.8)$, then Ni-bound proteins were eluted with $50 \mathrm{~mL}$ of $\mathrm{F}_{\mathrm{ab}}$ elution buffer ( $500 \mathrm{mM}$ imidazole, $500 \mathrm{mM} \mathrm{NaCl}, 50 \mathrm{mM}$ HEPES, $\mathrm{pH}$ 7.8). The eluted proteins were concentrated to $\leq 2 \mathrm{~mL}$ using Amicon Ultra Centrifugal Filters (Millipore Sigma) then further purified by size-exclusion chromatography ( $\mathrm{SEC}$, see below). All $\mathrm{F}_{\mathrm{ab}} \mathrm{S}$ used in binding experiments, enzyme reactions, crystallography, or SEC-SAXS were in the SEC-purified form.

Size-exclusion chromatography (SEC) purification of DEBS proteins and $F_{a b} S$

Concentrated protein samples $(\leq 2 \mathrm{~mL})$ or gel-filtration standards (Bio-Rad, catalog \# 1511901) were

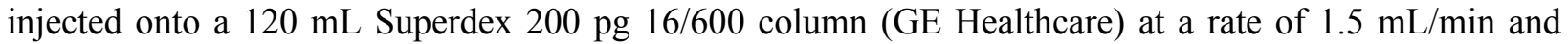
fractionated into $3 \mathrm{~mL}$ using an ÄKTA Pure protein purification FPLC system (GE Healthcare) with the following running buffers: SEC buffer 1 ( $250 \mathrm{mM} \mathrm{NaCl}, 10 \mathrm{mM}$ HEPES, $\mathrm{pH}$ 8.0: for crystallography, stand-alone KR1 reactions, binding experiments, and standard curve generation); SEC buffer 2 (100 mM citrate, $100 \mathrm{mM} \mathrm{NaCl}, 10 \mathrm{mM}$ HEPES, $\mathrm{pH}$ 7.2: for SEC-SAXS and M3/1+TE hybrid DEBS bimodule/trimodule activity studies). Eluted fractions were evaluated for purity by SDS-PAGE, and pooled fractions were concentrated using Amicon Ultra Centrifugal Filters (Millipore Sigma), flash-frozen in liquid $\mathrm{N}_{2}$, then stored at $-80{ }^{\circ} \mathrm{C}$. Protein concentrations were determined prior to flash-freezing by the Bradford assay using BSA standards (Thermo Fisher Scientific).

\section{KRI and (5)MI(2) biotinylation}

To $200 \mu \mathrm{L}$ of KR1 or (5)M1(2) (2 mg/mL) in PBS buffer $1\left(140 \mathrm{mM} \mathrm{NaCl}, 10 \mathrm{mM} \mathrm{NaH}_{2} \mathrm{PO}_{4}, \mathrm{pH} 8.0\right)$ was added $100 \mu \mathrm{M}$ EZ-Link NHS-PEG ${ }_{12}$-Biotin (Thermo Fisher Scientific, catalog \# 21313). The reaction was allowed to proceed for $30 \mathrm{~min}$ at room temperature then immediately transferred to a 7 MWCO Zeba Spin Desalting Column (Thermo Fisher Scientific, catalog \# 89883) equilibrated with PBS buffer 2 (140 mM 
$\mathrm{NaCl}, 10 \mathrm{mM} \mathrm{NaH} \mathrm{PO}_{4}, \mathrm{pH}$ 7.2) to remove the unreacted NHS-esters. The desalting procedure was performed per the manufacturer instructions using PBS buffer 2 as eluant. The extent of biotinylation was determined spectrophotometrically to be 1.2-fold biotin per KR1 (referred to as "KR1-biotin") and 1.5-fold biotin per (5)M1(2) (referred to as "(5)M1(2)-biotin") using a Pierce Biotin Quantitation Kit (Thermo Fisher Scientific, catalog \# 28005) and following the manufacturer instructions.

\section{KRI- $F_{a b}$ binding by enzyme-linked immunosorbent assay (ELISA)}

Similar to previous methods, wells of 96-well, clear Nunc Maxisorp plates (Invitrogen, catalog \# 44-240421) were coated with $50 \mu \mathrm{L}$ of streptavidin $(5 \mu \mathrm{g} / \mathrm{mL})$ in PBS buffer 2 overnight at $4{ }^{\circ} \mathrm{C}$. Wells were washed twice with PBS buffer 1 then blocked with $300 \mu \mathrm{L}$ of PBS containing $4 \%(\mathrm{w} / \mathrm{v})$ BSA for $1 \mathrm{~h}$ at room temperature. Wells were washed three times with phosphate buffer $\left(100 \mathrm{mM} \mathrm{NaH}_{2} \mathrm{PO}_{4} \mathrm{pH} 7.2\right)$, then $50 \mu \mathrm{L}$ KR1-biotin $(2.5 \mu \mathrm{g} / \mathrm{mL}$ in phosphate buffer $+2 \%$ BSA $)$ was added to each well. Plates were shaken at room temperature for $1 \mathrm{~h}$, then wells were washed three times with phosphate buffer. $\mathrm{F}_{\mathrm{ab}} \mathrm{s}$ (i.e., 1D10-FLAG and $2 \mathrm{G} 10-\mathrm{Myc}$ ) were serially diluted in phosphate buffer $+2 \% \mathrm{BSA}$ then $50 \mu \mathrm{L}$ of each dilution were added to wells and incubated with shaking for $2 \mathrm{~h}$ at room temperature. [In cases featuring coenzyme A or NADPH (Fig. 1B,C), prior to the addition of $\mathrm{F}_{\mathrm{ab}} \mathrm{s}, 25 \mu \mathrm{L}$ of cofactors (in phosphate buffer $+2 \% \mathrm{BSA}$ ) at 2-fold elevated concentration relative to Figure $1 \mathrm{~B}, \mathrm{C}$ were added to each well. After shaking plates for $1 \mathrm{~h}$ at room temperature, $25 \mu \mathrm{L}$ of $\mathrm{F}_{\mathrm{ab}} \mathrm{S}$ at 2-fold elevated concentration relative to Figure 1B,C were added to each well and plates were shaken for $2 \mathrm{~h}$ at room temperature]. Wells were washed three times with phosphate buffer $+0.005 \%(\mathrm{v} / \mathrm{v})$ Tween-20 followed by the addition of $50 \mu \mathrm{L}$ of $0.125 \mu \mathrm{g} / \mathrm{mL}$ anti-FLAG (BioLegend, catalog \# 637311) or 1/2500-fold diluted anti-Myc (Millipore Sigma, catalog \# 16-213) antibodies conjugated to horse radish peroxidase (HRP) and prepared in phosphate buffer $+2 \%$ BSA. Plates were shaken at room temperature for $1 \mathrm{~h}$, then wells were washed three times with phosphate buffer $+0.005 \%$ (v/v) Tween-20 and once with phosphate buffer before adding $100 \mu \mathrm{L}$ of 3,3',5,5'-tetramethylbenzidine (TMB) soluble solution (Millipore Sigma, catalog \# 613544) to each well. Reactions were developed for 1 min (anti-Flag-HRP wells) or 2 min (anti-Myc-HRP wells) before quenching with $100 \mu \mathrm{L}$ of $0.5 \mathrm{M} \mathrm{H}_{2} \mathrm{SO}_{4}$. Absorbance at $450 \mathrm{~nm}$ in each well was measured using a BioTek Synergy HT plate reader at ambient temperature. Data were plotted and curve fitted using OriginPro (Fig. 1B,C and Supporting Fig. S1).

\section{(5)M1(2)- $F_{a b}$ binding and competition binding by ELISA}

An identical procedure as above for $\mathrm{KR} 1-\mathrm{F}_{\mathrm{ab}}$ binding by ELISA was carried out with the following exceptions: [1] phosphate buffer was replaced with phosphate buffer $2\left(50 \mathrm{mM} \mathrm{NaH}_{2} \mathrm{PO}_{4} \mathrm{pH} 7.2\right)$; [2] 50 $\mu \mathrm{L} 20 \mu \mathrm{g} / \mathrm{mL}$ (5)M1(2)-biotin were added to each well; [3] Simultaneous with the addition of $\mathrm{F}_{\mathrm{ab}} \mathrm{s}$, KR1 (100 nM), (5)M1(2) (100 nM), LM(4) (2 $\mu \mathrm{M}),(3) \mathrm{M} 2(2)(2 \mu \mathrm{M}), \mathrm{M} 3(2 \mu \mathrm{M}),(3) \mathrm{M} 2+\mathrm{TE}(2 \mu \mathrm{M})$, or M3+TE $(2 \mu \mathrm{M})$ were co-incubated in wells containing (5)M1(2)-biotin; [4] Tween-20 concentration was increased to $0.05 \%(\mathrm{v} / \mathrm{v})$.

\section{Inhibition studies of stand-alone KR1 with $F_{a b}$ S $1 D 10$ and $2 G 10$}

$\mathrm{KR} 1(8 \mu \mathrm{M})$ was incubated with $8 \mu \mathrm{M}, 24 \mu \mathrm{M}$, or $48 \mu \mathrm{M} \mathrm{F}_{\mathrm{ab}}$ or SEC buffer 1 for 15 min at room temperature prior to their addition $(5 \mu \mathrm{L})$ to wells (clear-bottom 384-well plates, Corning, product \# 3765) containing $15 \mu \mathrm{L}$ of $133 \mathrm{mM} \mathrm{NaH}_{2} \mathrm{PO}_{4} \mathrm{pH}$ 7.3, $2.7 \mathrm{mM}$ trans-1-decalone (T1D), and $1.1 \mathrm{mM}$ NADPH (final reaction concentrations: $100 \mathrm{mM} \mathrm{NaH} \mathrm{PO}_{4} \mathrm{pH} 7.3,2 \mathrm{mM}$ TID, $0.8 \mathrm{mM}$ NADPH, $2 \mu \mathrm{M} \mathrm{KR} 1$, and $\{0-12 \mu \mathrm{M} \mathrm{F}$ ab; final reaction volume: $20 \mu \mathrm{L}$ ). Reaction progress was monitored by measuring absorbance at $340 \mathrm{~nm}$ every $15 \mathrm{~s}$ using a BioTek Synergy HT plate reader at ambient temperature.

Inhibition studies of bimodular DEBS with $F_{a b} s 1 D 10$ and $2 G 10$

An enzyme premix containing $2 \mathrm{mM}$ sodium propionate, $4 \mathrm{mM}$ methylmalonate, $8 \mu \mathrm{M} \mathrm{LDD}(4), 8 \mu \mathrm{M}$ (5)M1(2), and $8 \mu \mathrm{M}$ (3)M2+TE was incubated with $8 \mu \mathrm{M}, 24 \mu \mathrm{M}$, or $48 \mu \mathrm{M} \mathrm{F}$ ab or SEC buffer 1 for 15 min at room temperature prior to their addition $(5 \mu \mathrm{L})$ to wells (clear-bottom 384-well plates, Corning, product 
\# 3765) containing $15 \mu \mathrm{L}$ of $800 \mathrm{mM} \mathrm{NaH}_{2} \mathrm{PO}_{4} \mathrm{pH}$ 7.3, $6.7 \mathrm{mM}$ tris-(2-carboxyethyl)phosphine (TCEP), $13.3 \mathrm{mM} \mathrm{MgCl} 2,2 \mathrm{mM}$ coenzyme A (CoA), $8 \mathrm{mM}$ adenosine triphosphate (ATP), $1.1 \mathrm{mM}$ NADPH, 2.7 $\mu \mathrm{M}$ E. coli propionyl-CoA synthetase $(\operatorname{PrpE})^{4}, 2.7 \mu \mathrm{M}$ S. coelicolor methylmalonyl-CoA synthetase $(\mathrm{MatB})^{5,6}$, and $5.3 \mu \mathrm{M} \quad S$. coelicolor methylmalonyl-CoA epimerase (SCME) ${ }^{6}$ (final reaction concentrations: $600 \mathrm{mM} \mathrm{NaH}_{2} \mathrm{PO}_{4} \mathrm{pH}$ 7.3, $5 \mathrm{mM}$ TCEP, $10 \mathrm{mM} \mathrm{MgCl}_{2}, 1.5 \mathrm{mM} \mathrm{CoA}, 6 \mathrm{mM} \mathrm{ATP}, 0.8 \mathrm{mM}$ NADPH, $0.5 \mathrm{mM}$ sodium propionate, $1 \mathrm{mM}$ methylmalonate, $2 \mu \mathrm{M}$ PrpE, $2 \mu \mathrm{M}$ MatB, $4 \mu \mathrm{M}$ SCME, $2 \mu \mathrm{M}$ $\mathrm{LDD}(4), 2 \mu \mathrm{M}$ (5)M1(2), $2 \mu \mathrm{M}$ (3)M2+TE, and $\left\{0-12 \mu \mathrm{M} \mathrm{F}_{\mathrm{ab}}\right\}$; final reaction volume: $\left.20 \mu \mathrm{L}\right)$. Reaction progress was monitored by measuring absorbance at $340 \mathrm{~nm}$ every $15 \mathrm{~s}$ using a BioTek Synergy HT plate reader at ambient temperature.

\section{Analysis of T1D reduction by KRI and characterization of its inhibition by $1 D 10$}

To determine the mode of 1D10 inhibition, we first measured the effect of T1D concentration on the rate of reduction by KR1 to ensure T1D binding is not rate-limiting. Accordingly, T1D was serially diluted from $400-1.6 \mathrm{mM}$ (in water), $5 \mu \mathrm{L}$ of which were added to $15 \mu \mathrm{L}$ of $133 \mathrm{mM} \mathrm{NaH}_{2} \mathrm{PO}_{4} \mathrm{pH} 7.3,1.1 \mathrm{mM} \mathrm{NADPH}$, and $0.67 \mu \mathrm{M}$ KR1 (final reaction concentrations: $100 \mathrm{mM} \mathrm{NaH}_{2} \mathrm{PO}_{4} \mathrm{pH} 7.3,\{100-0.4 \mathrm{mM}$ T1D $\}, 0.8 \mathrm{mM}$ $\mathrm{NADPH}$, and $0.5 \mu \mathrm{M} \mathrm{KR} 1$; final reaction volume: $20 \mu \mathrm{L}$ ). A similar reaction was analyzed in which $5 \mu \mathrm{L}$ of water diluent (not T1D) was added to the $15 \mu \mathrm{L}$ cocktail above. Reaction progress in clear-bottom 384well plates (Corning, product \# 3765) was monitored by measuring absorbance at $340 \mathrm{~nm}$ every $15 \mathrm{~s}$ using a BioTek Synergy HT plate reader at ambient temperature. A dose-dependent increase in enzyme velocity was observed that appears to plateau around $20 \mathrm{mM}$; although, inconsistencies were observed in the initial rates at high T1D concentrations, likely due to the moderate water solubility of T1D (Supporting Fig. S2A). Therefore, we selected $15 \mathrm{mM}$ as a compromising T1D concentration to use in the following reactions varying $1 \mathrm{D} 10$ and NADPH.

To measure the NADPH dynamic range, five different NADPH concentrations were tested in similar KR1 reactions by serially diluting from $3.2-0.2 \mathrm{mM}$ (in water). $7.5 \mu \mathrm{L}$ of each dilution were added to $22.5 \mu \mathrm{L}$ of $133 \mathrm{mM} \mathrm{NaH} \mathrm{PO}_{4} \mathrm{pH} 7.3,20 \mathrm{mM} \mathrm{T1D}$, and $0.67 \mu \mathrm{M} \mathrm{KR} 1$ (final reaction concentrations: $100 \mathrm{mM}$ $\mathrm{NaH}_{2} \mathrm{PO}_{4} \mathrm{pH} 7.3,15 \mathrm{mM}$ T1D, $\{0.8-0.05 \mathrm{mM} \mathrm{NADPH}\}$, and $0.5 \mu \mathrm{M} \mathrm{KR} 1$; final reaction volume: 30 $\mu \mathrm{L}$ ). Reaction progress in clear-bottom 384-well plates (Corning, product \# 3765) was monitored by measuring absorbance at $340 \mathrm{~nm}$ every $15 \mathrm{~s}$ using a BioTek Synergy HT plate reader at ambient temperature (Supporting Fig. S2B).

$1 \mathrm{D} 10$ concentration was varied in KR1/T1D reduction reactions to measure its corresponding $\mathrm{IC}_{50}$ value. After serially diluting 1D10 from $180-2.8 \mu \mathrm{M}$ (in SEC buffer 1), each dilution was combined with $2 \mu \mathrm{M}$ $\mathrm{KR} 1$ and incubated for $15 \mathrm{~min}$ at room temperature. $5 \mu \mathrm{L}$ of the KR1/1D10 mixtures were added to $15 \mu \mathrm{L}$ of $133 \mathrm{mM} \mathrm{NaH}{ }_{2} \mathrm{PO}_{4} \mathrm{pH} 7.3,20 \mathrm{mM} \mathrm{T1D}$, and $1.1 \mathrm{mM} \mathrm{NADPH}$ (final reaction concentrations: $100 \mathrm{mM}$ $\mathrm{NaH}_{2} \mathrm{PO}_{4} \mathrm{pH} 7.3,15 \mathrm{mM}$ T1D, $0.8 \mathrm{mM}$ NADPH, $\{45-0.7 \mu \mathrm{M} 1 \mathrm{D} 10\}$, and $0.5 \mu \mathrm{M} \mathrm{KR} 1$; final reaction volume: $20 \mu \mathrm{L}$ ). Reaction progress in clear-bottom 384-well plates (Corning, product \# 3765) was monitored by measuring absorbance at $340 \mathrm{~nm}$ every $15 \mathrm{~s}$ using a BioTek Synergy HT plate reader at ambient temperature (Supporting Fig. S3).

These three experiments informed the next experiment which varied both NADPH and 1D10 concentration. Here, $1 \mathrm{D} 10$ was titrated from $90-11.3 \mu \mathrm{M}$ (in SEC buffer 1) and dilutions were combined with $2 \mu \mathrm{M}$ KR1 and incubated for $15 \mathrm{~min}$ at room temperature, including one sample with the diluent SEC buffer 1 in place of 1D10. Separately, NADPH was titrated from $666.7-83.3 \mu \mathrm{M}$ in solution containing $133 \mathrm{mM} \mathrm{NaH}_{2} \mathrm{PO}_{4}$ $\mathrm{pH} 7.3$ and $20 \mathrm{mM}$ T1D. $7.5 \mu \mathrm{L}$ of the KR1/1D10 mixture was added to $22.5 \mu \mathrm{L}$ of the $\mathrm{NADPH} / \mathrm{NaH}_{2} \mathrm{PO}_{4} / \mathrm{T} 1 \mathrm{D}$ mixtures in a $4 \times 5$ grid of reactions in clear-bottom 384-well plates (Corning, product \# 3765; final reaction concentrations: $100 \mathrm{mM} \mathrm{NaH}_{2} \mathrm{PO}_{4} \mathrm{pH} 7.3,15 \mathrm{mM}$ T1D, $\{500-62.5 \mu \mathrm{M}$ $\mathrm{NADPH}\},\{22.5-2.8 \mu \mathrm{M}$ and $0 \mu \mathrm{M} 1 \mathrm{D} 10\}$, and $0.5 \mu \mathrm{M} \mathrm{KR} 1$; final reaction volume: $30 \mu \mathrm{L})$ that were 
monitored by measuring absorbance at $340 \mathrm{~nm}$ every $15 \mathrm{~s}$ using a BioTek Synergy HT plate reader at ambient temperature (Supporting Fig. S4).

Reduction of T1D catalyzed by KR1, M3/1+TE, M3+TE, and (5)M1(2)

Reactions $(30 \mu \mathrm{L})$ in wells of clear-bottom 384-well plates (Corning, product \# 3765) containing $100 \mathrm{mM}$ $\mathrm{NaH}_{2} \mathrm{PO}_{4} \mathrm{pH} 7.3,15 \mathrm{mM}$ T1D, $0.5 \mathrm{mM}$ NADPH, and $2 \mu \mathrm{M}$ enzyme (i.e., either KR1, M3/1+TE, M3+TE, or (5)M1(2)), in addition to one control reaction lacking enzyme, were monitored by measuring absorbance at $340 \mathrm{~nm}$ every $10 \mathrm{~s}$ using a BioTek Synergy HT plate reader at ambient temperature (Supporting Fig. S9).

Crystallization of KRI-F $F_{a b}$ complexes and crystal mounting

KR1 was incubated with $1 \mathrm{D} 10$ or $2 \mathrm{G} 10$ (1.5 equiv.) on ice for $30 \mathrm{~min}$ prior to purification of the complexes by SEC (above). Elution fractions corresponding to peaks with reduced retention volume relative to KR1, containing the KR1- $\mathrm{F}_{\mathrm{ab}}$ complexes (verified by SDS-PAGE), were concentrated using Amicon Ultra Centrifugal Filters (Millipore Sigma) and directly used in crystallography experiments.

$\underline{\text { KR1-1D10 }}$ was cocrystallized in hanging drops by combining $1 \mu \mathrm{L}$ of $6 \mathrm{mg} / \mathrm{mL}$ KR1-1D10 complex with $1 \mu \mathrm{L}$ of reservoir solution containing $1.9 \mathrm{M}\left(\mathrm{NH}_{4}\right)_{2} \mathrm{SO}_{4}$ and $0.1 \mathrm{M}$ tris $\mathrm{pH}$ 7.5. Drops were equilibrated over $1 \mathrm{~mL}$ of similar reservoir solution at $12^{\circ} \mathrm{C}$ for $48 \mathrm{~h}$ before triangular crystals reached a maximum width of approximately $500 \mu \mathrm{m}$. Crystals of KR1-1D10 were immersed in its reservoir solution supplemented with $10 \%$ ethylene glycol prior to mounting and plunging in liquid $\mathrm{N}_{2}$.

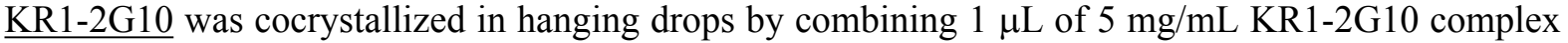
with $1 \mu \mathrm{L}$ of reservoir solution containing $15 \%(\mathrm{w} / \mathrm{v})$ polyethylene glycol (PEG) $6000,5 \%(\mathrm{v} / \mathrm{v}) 2$ 2methyl-2,4-pentanediol (MPD), and 0.1 M MES pH 6.5. Drops were equilibrated over $1 \mathrm{~mL}$ of similar reservoir solution at $12{ }^{\circ} \mathrm{C}$ for $48 \mathrm{~h}$ before rod-shaped crystals reached a maximum length of approximately $1 \mathrm{~mm}$. Crystals of KR1-2G10 were immersed in its reservoir solution supplemented with $18 \%$ ethylene glycol prior to mounting and plunging in liquid $\mathrm{N}_{2}$.

$X$-ray diffraction data collection, data processing, and determination of KR $1-F_{a b}$ structures

Data were collected at beamlines 14-1 (KR1-1D10) and 12-2 (KR1-2G10) at the Stanford Synchrotron Radiation Lightsource (SSRL) at SLAC (for additional experimental details see PDB entries 6WH9 and 6W7S). Diffraction images were processed using autoPROC ${ }^{7}$ to obtain the scaled and merged reflections. The structures were solved by molecular replacement in Phenix Phaser ${ }^{8}$ using the previously solved KR1 coordinates and $\mathrm{F}_{\mathrm{ab}}$ homology models ${ }^{9}$ as search models. Initial models were built using Buccaneer ${ }^{10}(\mathrm{KR} 1-$ 1D10) or Phenix Autobuild ${ }^{11}$ (KR1-2G10). Model improvements were achieved through iterative cycles of automated refinement in Phenix Refine ${ }^{12}$ and/or REFMAC5 ${ }^{13}$ combined with manual model fitting in $\operatorname{Coot}^{14}$.

Testing enzymatic activity of M3/1+TE within a DEBS bimodule or trimodule

Reactions $(30 \mu \mathrm{L})$ were prepared by combining $600 \mathrm{mM} \mathrm{NaH}_{2} \mathrm{PO}_{4} \mathrm{pH} 7.3,5 \mathrm{mM}$ TCEP, $10 \mathrm{mM} \mathrm{MgCl}$, $1.5 \mathrm{mM}$ CoA, $6 \mathrm{mM}$ ATP, $2 \mu \mathrm{M}$ PrpE, $2 \mu \mathrm{M}$ MatB, $4 \mu \mathrm{M}$ SCME, $2 \mu \mathrm{M}$ LDD(4), and $2 \mu \mathrm{M}$ (5)M1(2) with the following additional DEBS enzymes:

Bimodular (hybrid) DEBS: $2 \mu \mathrm{M}$ (3)M2+TE (black squares, Supporting Fig. S8B) or $6 \mu \mathrm{M}$ M3/1+TE (red circles, Supporting Fig. S8B). In another instance, the same preparation was made with buffer A in place of a TE-containing enzyme (single turnover control; blue triangles, Supporting Fig. S8B).

Trimodular (hybrid) DEBS: $6 \mu \mathrm{M}(3) \mathrm{M} 2(2)$ and $6 \mu \mathrm{M} \mathrm{M} 3+\mathrm{TE}$ (black squares, Fig. 4B) or $6 \mu \mathrm{M}$ (3) $\mathrm{M} 2(2)$ and $6 \mu \mathrm{M} \mathrm{M} 3 / 1+\mathrm{TE}$ (red circles, Fig. 4B). In another instance, the same preparation was 
made with buffer A in place of a TE-containing enzyme (single turnover control; blue triangles, Fig. 4B).

To initiate the above prepared reaction mixtures, $0.5 \mathrm{mM}$ sodium propionate, $1 \mathrm{mM}$ methylmalonate, and $0.8 \mathrm{mM}$ NADPH were added, then reaction solutions were transferred to multi-titer plate wells (clearbottom 384-well plates, Corning, product \# 3765) and absorbance at $340 \mathrm{~nm}$ was measured every $14 \mathrm{~s}$ using a BioTek Synergy HT plate reader at ambient temperature.

\section{Liquid chromatography mass spectrometry (LC-MS) analysis of hybrid and native trimodular DEBS} reaction products

To remove proteins and salt from above reaction mixtures, an equal volume of methanol was added and the suspension clarified at 15,000 RCF for $10 \mathrm{~min}$ at room temperature. The supernatant was analyzed by LCMS using an Agilent 1290 Infinity II LC system equipped with an Agilent 6470 triple quadrupole mass spectrometer. Analytes $(10 \mu \mathrm{L})$ were injected onto a Zorbax RRHD Extended-C18 column $(2.1 \mathrm{x} 50 \mathrm{~mm}$, $1.8 \mu \mathrm{m}$ ) with a flow-rate of $0.4 \mathrm{~mL} / \mathrm{min}$ and the column maintained at $40{ }^{\circ} \mathrm{C}$. A gradient elution was established by flowing two solvents (i.e., solvent $\mathrm{A}=99.9 \%$ water $+0.1 \%$ formic acid; solvent $\mathrm{B}=99.9 \%$ acetonitrile $+0.1 \%$ formic acid) at $0.4 \mathrm{~mL} / \mathrm{min}$ from $5-95 \%$ solvent $\mathrm{B}$ over $4 \mathrm{~min}$, and mass spectra were collected in positive ion mode.

SEC-SAXS analysis of $F_{a b}-M 3 / 1+T E$ complexes

Prior to SEC-SAXS, $\mathrm{F}_{\mathrm{ab}}-\mathrm{M} 3 / 1+\mathrm{TE}$ complexes were isolated by incubating 1.2 equivalents of $\mathrm{F}_{\mathrm{ab}}$ per $\mathrm{M} 3 / 1+\mathrm{TE}$ for $30 \mathrm{~min}$ on ice $(200 \mu \mathrm{L})$ then purifying by SEC using SEC buffer $2(100 \mathrm{mM}$ citrate, $100 \mathrm{mM}$ $\mathrm{NaCl}, 10 \mathrm{mM}$ HEPES, pH 7.2), as described above. The purified complexes (Supporting Fig. S10) were concentrated to $\geq 10 \mathrm{mg} / \mathrm{mL}$ using Amicon Ultra Centrifugal Filters (Millipore Sigma). The SEC-SAXS experiments were carried out at the Stanford Synchrotron Radiation Light Source (SSRL) Bio-SAXS beamline 4-2 in a similar manner as previously reported ${ }^{15,16}$. Experimental setup and structural parameters are summarized in Supporting Table S2. The SEC columns (Superose 6 Increase 3.2/300, GE Healthcare) were well equilibrated with the SEC buffer 2 before SEC-SAXS data collection. A series of different injection volumes $(5-20 \mu \mathrm{L})$ was tested to optimize the results. In total, 550 images were recorded with 1 $\mathrm{s}$ exposure every $5 \mathrm{~s}$ at a flow rate of $0.04 \mathrm{~mL} / \mathrm{min}$. Automatic data reduction and initial analyses were performed using SECPipe, an automated SEC-SAXS real-time processing and analysis pipeline at SSRL beamline 4-2 (https://www-ssrl.slac.stanford.edu/smb-saxs/node/1860). The SECPipe implements a data reduction program, SASTOOL (https://www-ssrl.slac.stanford.edu/smb-saxs/node/1914) and an automatic Guinier analysis program, ATSAS AUTORG ${ }^{17}$. The first 100 images at the early part of the void volume were averaged and used as a buffer-scattering profile for background subtraction. After taking the first 100 images, the X-ray shutter was closed until the main peak eluted so as to keep the sample cell clean from radiation-damaged sample. The data were then presented as $\mathrm{I}(q)$ versus $q$, where $q=4 \sin (\theta) / \lambda, 2 \theta$ is the scattering angle, and $\lambda$ is the X-ray wavelength. The scattering intensities were converted to absolute scale using water ${ }^{18}$. The program GNOM was used for the indirect Fourier transform to estimate the distance distribution function $P(\mathrm{r})^{19}$. The theoretical scattering profiles of the models were computed and fitted with experimental data using the program $\mathrm{CRYSOL}^{20}$. Ab initio SAXS envelopes were generated using $\mathrm{DAMMIF}^{21}$ with the following parameters: mode $=$ slow; repetitions $=20$; symmetry $=\mathrm{P} 2$; anisometry $=$ unknown. As a caveat, considerable model ambiguity was determined using AMBIMETER ${ }^{22}$; that is, 87 compatible shapes can be generated from the 1B2-M3/1+TE data (ambiguity score $=1.94$ ) and, similarly, 136 compatible shapes from the 1D10-M3/1+TE data (ambiguity score $=2.13$ ). 


\section{Protein Sequences}

\section{Hybrid DEBS module M3/1+TE}

(3) KS3-AT3-KR1-ACP1-TE

MASTDSEKVAEYLRRATLDLRAARQRIRELESDPIAIVSMACRLPGGVNTPQRLWELLREGGETLSGFPT DRGWDLARLHHPDPDNPGTSYVDKGGFLDDAAGFDAEFFGVSPREAAAMDPQQRLLLETSWELVENAGID PHSLRGTATGVFLGVAKFGYGEDTAAAEDVEGYSVTGVAPAVASGRISYTMGLEGPS ISVDTACSSSLVA LHLAVESLRKGESSMAVVGGAAVMATPGVFVDFSRQRALAADGRSKAFGAGADGFGFSEGVTLVLLERLS EARRNGHEVLAVVRGSALNQDGASNGLSAPSGPAQRRVIRQALESCGLEPGDVDAVEAHGTGTALGDPIE ANALLDTYGRDRDADRPLWLGSVKSNIGHTQAAAGVTGLLKVVLALRNGELPATLHVEEPTPHVDWSSGG VALLAGNQPWRRGERTRRARVSAFGISGTNAHVIVEEAPEREHRETTAHDGRPVPLVVSARTTAALRAQA AQIAELLERPDADLAGVGLGLATTRARHEHRAAVVASTREEAVRGLREIAAGAATADAVVEGVTEVDGRN VVFLFPGQGSQWAGMGAELLSSSPVFAGKIRACDESMAPMQDWKVSDVLRQAPGAPGLDRVDVVQPVLFA VMVSLAELWRSYGVEPAAVVGHSQGEIAAAHVAGALTLEDAAKLVVGRSRLMRSLSGEGGMAAVALGEAA VRERLRPWQDRLSVAAVNGPRSVVVSGEPGALRAFSEDCAAEGIRVRDI DVDYASHS PQIERVREELLET TGDIAPRPARVTFHSTVESRSMDGTELDARYWYRNLRETVRFADAVTRLAESGYDAFIEVSPHPVVVQAV EEAVEEADGAEDAVVVGSLHRDGGDLSAFLRSMATAHVSGVDIRWDVALPGAAPFALPTYPFQRKRYWLQ PAAPAAASDELAYRIEWRPTGAGEPARLDGTWLVAKYAGTADETSTAAREALESAGARVRELVVDARCGR DELAERLRSVGEVAGVLSLLAVDEAEPEEAPLALASLADTLSLVQAMVSAELGCPLWTVTESAVATGPFE RVRNAAHGALWGVGRVIALENPAVWGGLVDVPAGSVAELARHLAAVVSGGAGEDQLALRADGVYGRRWVR AAAPATDDEWKPTGTVLVTGGTGGVGGQIARWLARRGAPHLLLVSRS GPDADGAGELVAELEALGARTTV AACDVTDRESVRELLGGIGDDVPLSAVFHAAATLDDGTVDTLTGERIERASRAKVLGARNLHELTRELDL TAFVLFSSFASAFGAPGLGGYAPGNAYLDGLAQQRRSDGLPATAVAWGTWAGS GMAEGPVADRFRRHGVI EMPPETACRALQNALDRAEVCPIVIDVRWDRFLLAYTAQRPTRLFDEIDDARRAAPQAAAEPRVGALASL PAPEREKALFELVRSHAAAVLGHASAERVPADQAFAELGVDSLSALELRNRLGAATGVRLPTTTVFDHPD VRTLAAHLAAELGSGTPAREASSALRDGYRQAGVSGRVRSYLDLLAGLSDFREHFDGSDGFSLDLVDMAD GPGEVTVICCAGTAAISGPHEFTRLAGALRGIAPVRAVPQPGYEEGEPLPSSMAAVAAVQADAVIRTQGD KPFVVAGHSAGALMAYALATELLDRGHPPRGVVLIDVYP PGHQDAMNAWLEELTATLFDRETVRMDDTRL TALGAYDRLTGQWRPRETGLPTLLVSAGEPMGPWPDDSWKPTWPFEHDTVAVPGDHFTMVQEHADAIARH IDAWLGGGNSSSVDKLAAALEHHHHHH

\section{$1 B 2$ (heavy chain)}

MAEVQLVQSGGGLVQPGRSLRLSCTASGFTFGDYAMSWVRQAPGKGLEWVGFIRSKAYGGTTEYAASVKG RFTISRDDSKS IAYLQMNSLKTEDTAVYYCTRGGTLFDYWGQGTLVTVSSASTKGPSVFPLAPSSKSTSG GTAALGCLVKDYFPEPVTVSWNSGALTSGVHTFPAVLQSSGLYSLSSVVTVPSSSLGTQTYICNVNHKPS NTKVDKKVEPKSCAALVPRGSAHHHHHHAADYKDDDDKA

\section{$1 B 2$ (light chain)}

LFAI PLVVPFYSHSALDVVMTQSPLSLPVTPGEPAS ISCRSSQSLLHSNGYNYLDWYLQKPGQSPQLLIY LGSNRASGVPDRFSGSGSGTDFTLKISRVEAEDVGVYYCMQSLQTPRLTFGPGTKVDIKRTVAAPSVFIF PPSDEQLKSGTASVVCLLNNFYPRGAKVQWKVDNALQSGNSQESVTEQDSKDSTYSLSSTLTLSKADYEK HKVYACEVTHQGLSSPVTKSFNRGEC

\section{$1 D 10$ (heavy chain)}

MAEVQLVQSGAEVKKPGSSVKVSCKASGGTFSSYAISWVRQAPGQGLEWMGWISAYNGNTNYAQKLQGRV TMTTDTSTSTAYMELRSLRSDDTAVYYCARAPNYGDYVAFDIWGQGTTVTVSSASTKGPSVFPLAPSSKS TSGGTAALGCLVKDYFPEPVTVSWNSGALTSGVHTFPAVLQSSGLYSLSSVVTVPSSSLGTQTY ICNVNH KPSNTKVDKKVEPKSCAAAHHHHHHAADYKDDDDKA

\section{$1 D 10$ (light chain)}

LFAIPLVVPFYSHSAQTVVIQEPSLTVSPGGTVTLTCGSSTGAVTSGHYPYWFQQKPGQAPRTLIYDTSN KHSWTPARFSGSLLGGKAALTLSGAQPEDEAEYYCLLSYSGALWVFGGGTKLTVLGQPKAAPSVTLFPPS SEELQANKATLVCLISDFYPGAVTVAWKADSS PVKAGVETTTPSKQSNNKYAASSYLSLTPEQWKSRKSY SCQVTHEGSTVEKTVAPAECS 
2 G10 (heavy chain)

MAEVQLVQSGGGVVQPGRSLRLSCAASGFTFSSYAMHWVRQAPGKGLEWVAVISYDGSNKYYADSVKGRF TISRDNSKNTLYLQMNSLRAEDTAVYYCARAPIQVMVRGVMAPDYWGQGTLVTVSSASTKGPSVFPLAPS SKSTSGGTAALGCLVKDYFPEPVTVSWNSGALTSGVHTFPAVLQSSGLYSLSSVVTVPSSSLGTQTYICN VNHKP SNTKVDKKVEPKSCAAAHHHHHHGAAEQKLISEEDLNGAA

2 G10 (light chain)

LFAI PLVVPFYSHSAQAVLTQPSSLSASPGASASLTCTLRSGINVGTYRIYWYQQKPGSPPQYLLRYKSD SDKQQGSGVPSRFSGSKDASANAGILLISGLQSEDEADYYCMTWHSSAYVFGTGTKVTVLGQPKANPTVT LFPPSSEELQANKATLVCLISDFYPGAVTVAWKADGS PVKAGVETTKPSKQSNNKYAASSYLSLTPEQWK SHRSYSCQVTHEGSTVEKTVAPTECS 


\section{Supporting Figures}
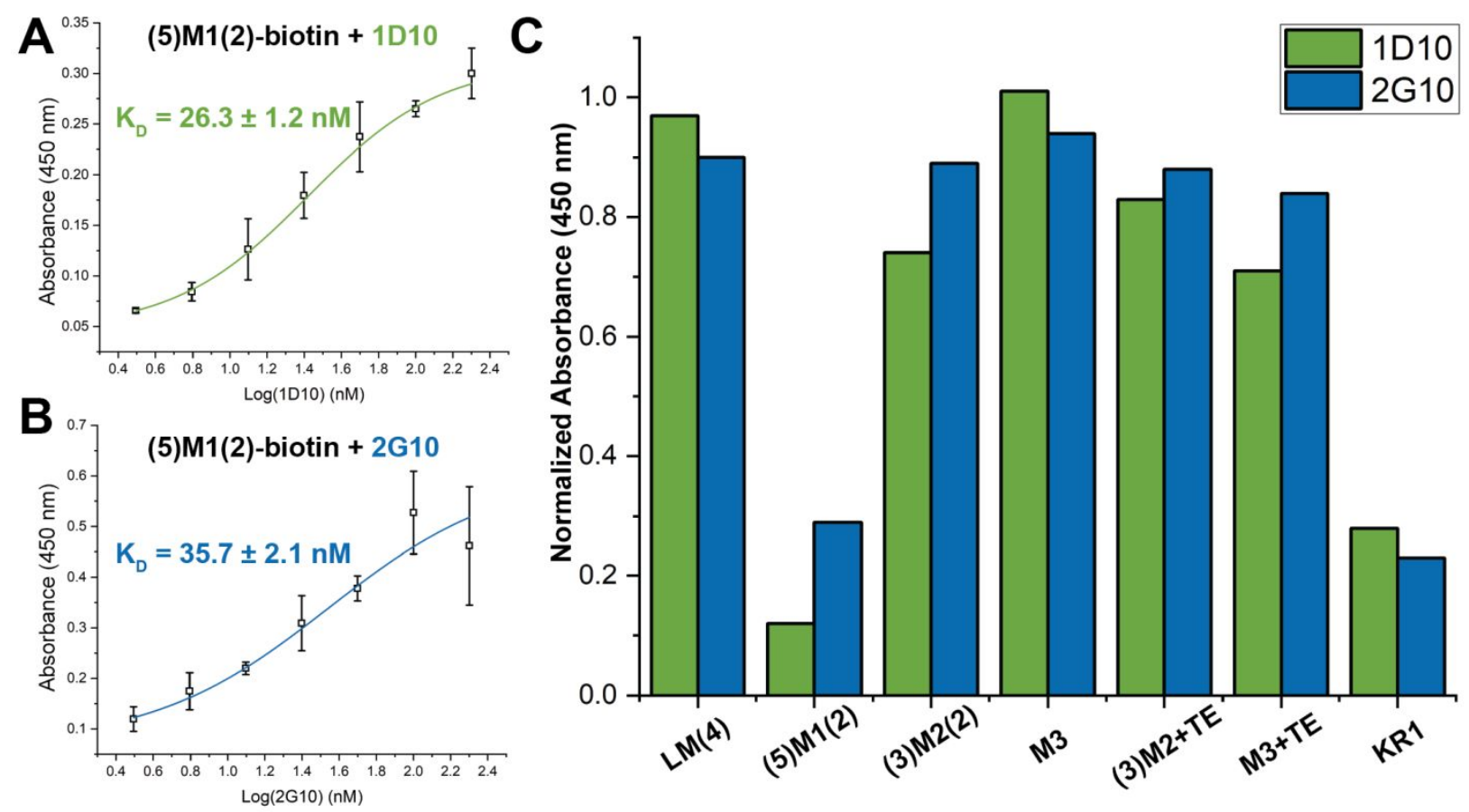

Figure S1: M1-specific $\mathrm{F}_{\mathrm{ab}} \mathrm{s}$ (A) 1D10 and (B) 2G10 binding against (5)M1(2)-biotin by ELISA (n=3). Error bars in panels A and B reflect the standard deviations of three replicate measurements (Supporting Methods). (C) Competition ELISA in which mobilized DEBS proteins (x-axis) were added to wells in addition to $1 \mathrm{D} 10$ and 2G10 (n=1). The $1 \mathrm{D} 10$ and 2G10 heavy chains contain a C-terminal FLAG and Myc tag, respectively, enabling their detection by antibodies conjugated to horseradish peroxidase. See Table S5 for the list of plasmids used to obtain these proteins and their associated references. 

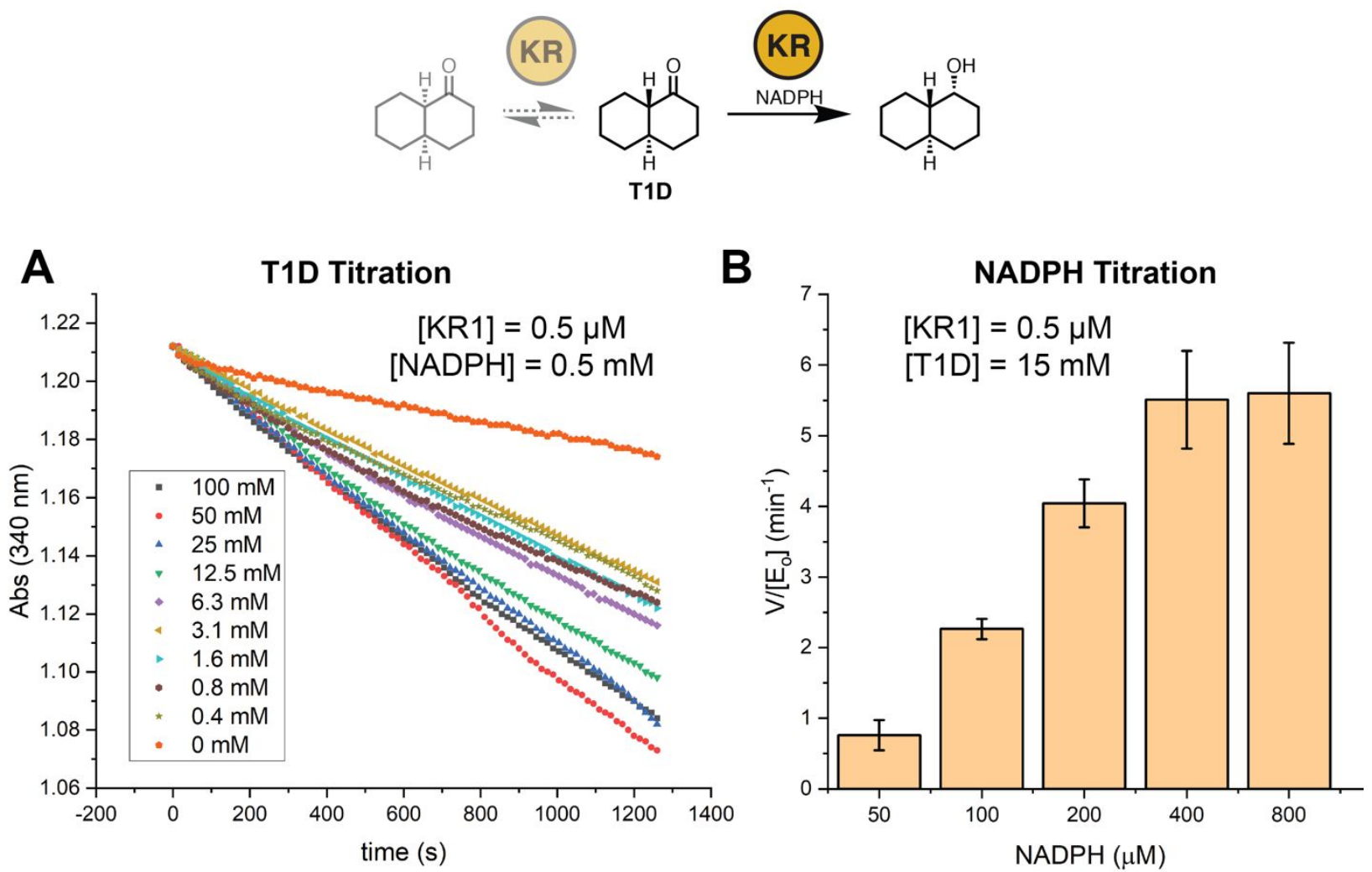

Figure S2: Dependence of KR1-mediated T1D reduction on (A) T1D concentration ( $n=1)$ and (B) NADPH concentration $(n=3)$. Error bars reflect the standard deviations of three replicate measurements. See Supporting Methods for reaction details. 


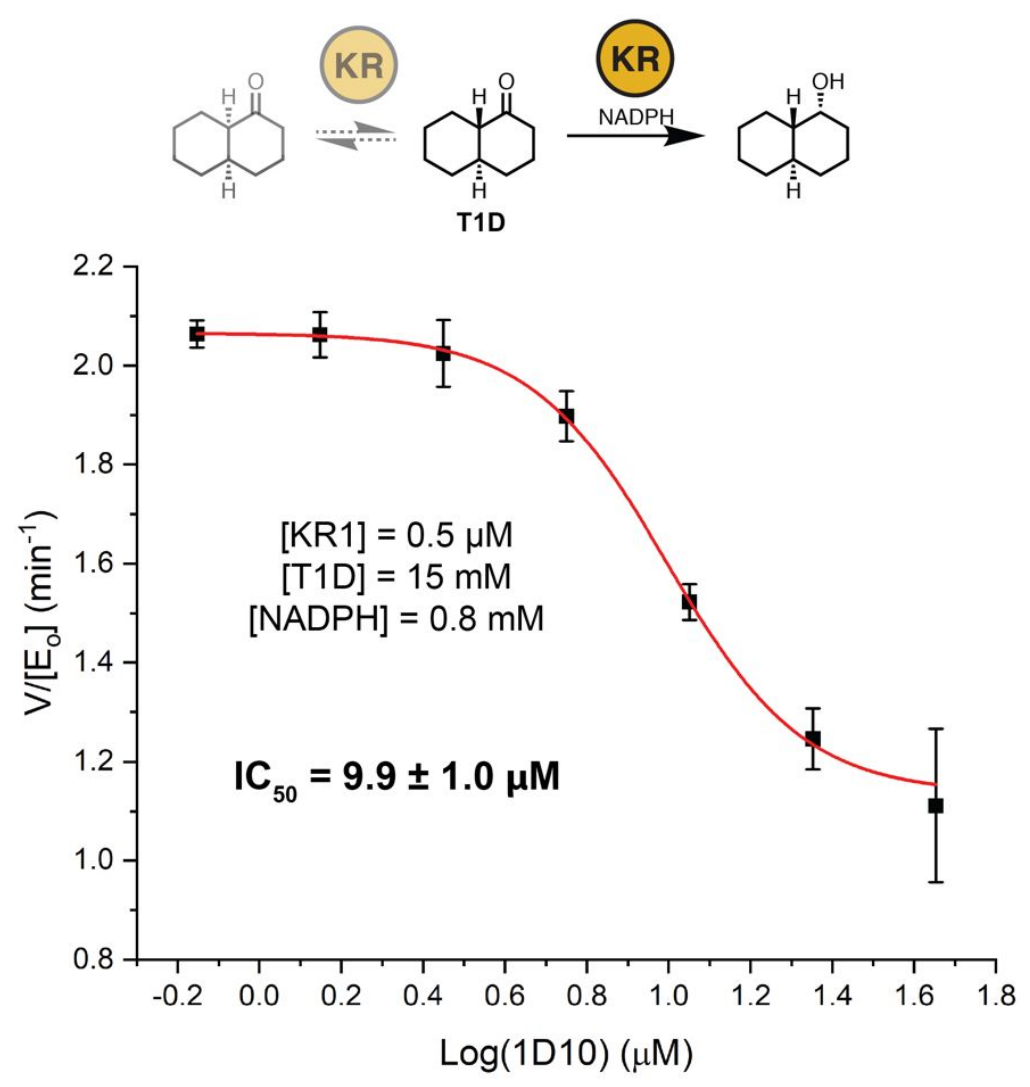

Figure S3: Dose-dependent inhibition of KR1-mediated T1D reduction by $1 D 10(n=3)$. The error bars reflect the standard deviations of three replicate measurements. See Supporting Methods for reaction details. 


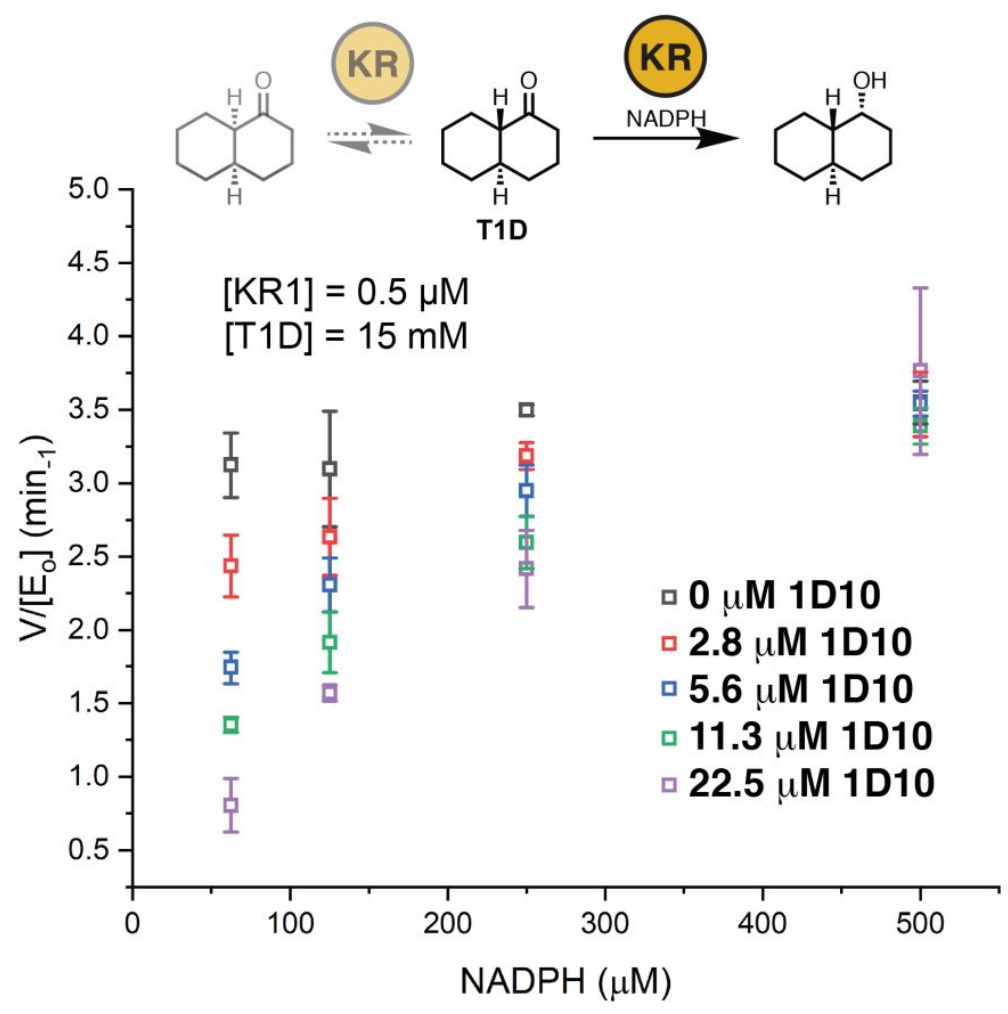

Figure S4: Dependence of KR1-mediated T1D reduction on NADPH concentration and 1D10 concentration $(n=3)$. The error bars reflect the standard deviations of three replicate measurements. See Supporting Methods for reaction details. 

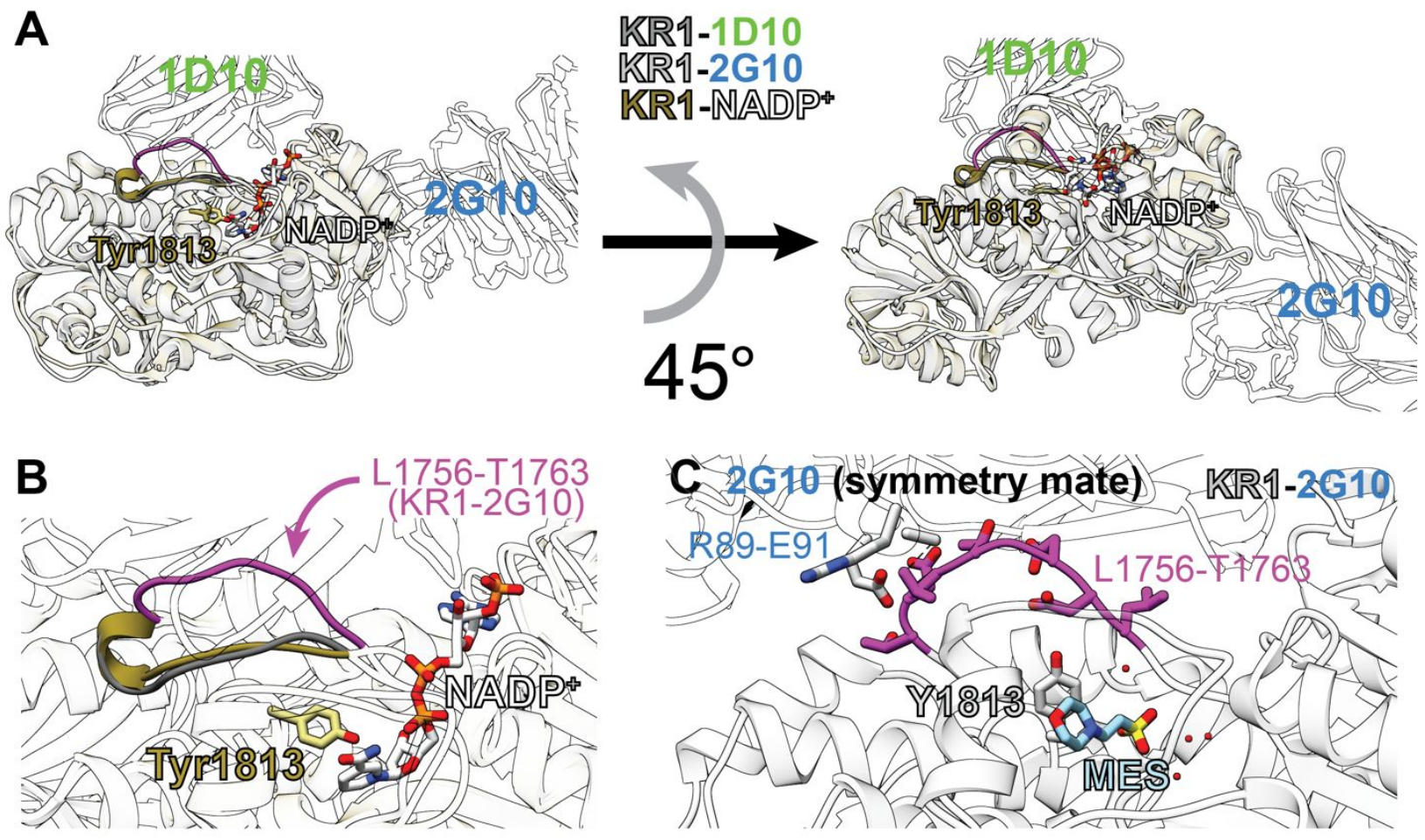

Figure S5: (A) KR1-1D10 and KR1-2G10 structures superposed with the KR1-NADP ${ }^{+}$structure $^{23}$ (average $\mathrm{RMSD}=0.705 \AA$ over 2595 atoms). An erratic loop in KR1-2G10 is shown in magenta corresponding to residues L1756-T1763 of KR1. The NADP ${ }^{+}$and catalytic Tyr1813 are shown as sticks in KR1-NADP ${ }^{+}$. (B) Close-up view of the KR1 erratic loop (L1756-T1763) of KR1-2G10 in the superposition of panel A. (C) Crystal lattice contacts between the erratic loop (L1756-T1763) and a neighboring 2G10 heavy chain. Convincing electron density for a 2-( $N$-morpholino)ethanesulfonic acid (MES, blue sticks) buffer molecule was observed near the NADP $(\mathrm{H})$ binding site. Selected crystallographic waters are shown as red spheres. 


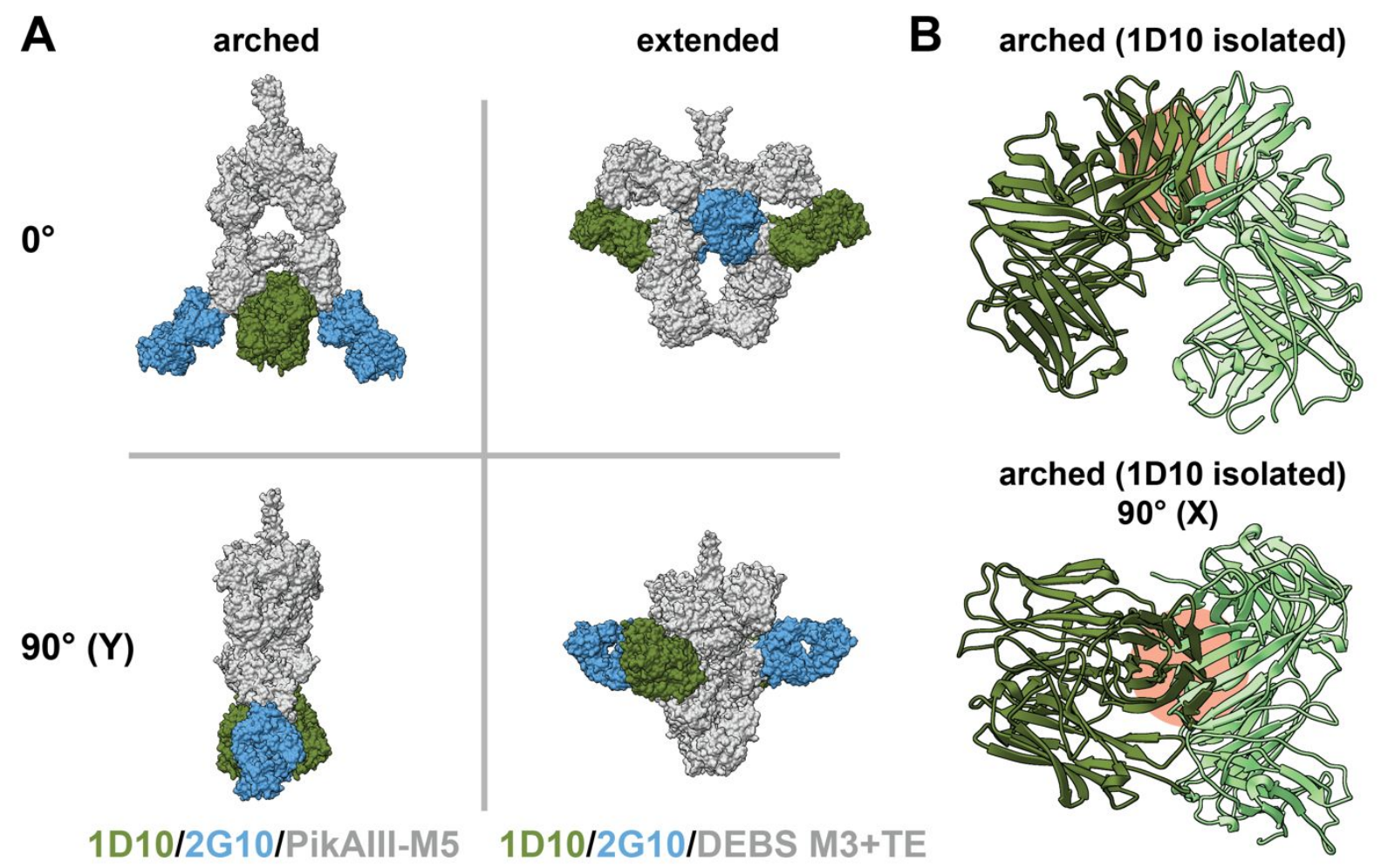

Figure S6: Superposition of the KR1-1D10 and KR1-2G10 structures onto the pikromycin synthase module 5 (PikAIII-M5) arched ${ }^{24,25}$ and DEBS module $3+$ thioesterase (DEBS M3+TE) extended $^{26}$ models of an $^{2}$ assembly-line PKS module. (A) Two $90^{\circ}$-related orientations are shown for each set of superpositions. (B) A close-up view of isolated 1D10 following superposition of KR1-1D10 onto the arched model. A ribbon diagram is shown for two 1D10 heterodimers (in dark green and light green, for clarity), highlighting the subunit overlap. 

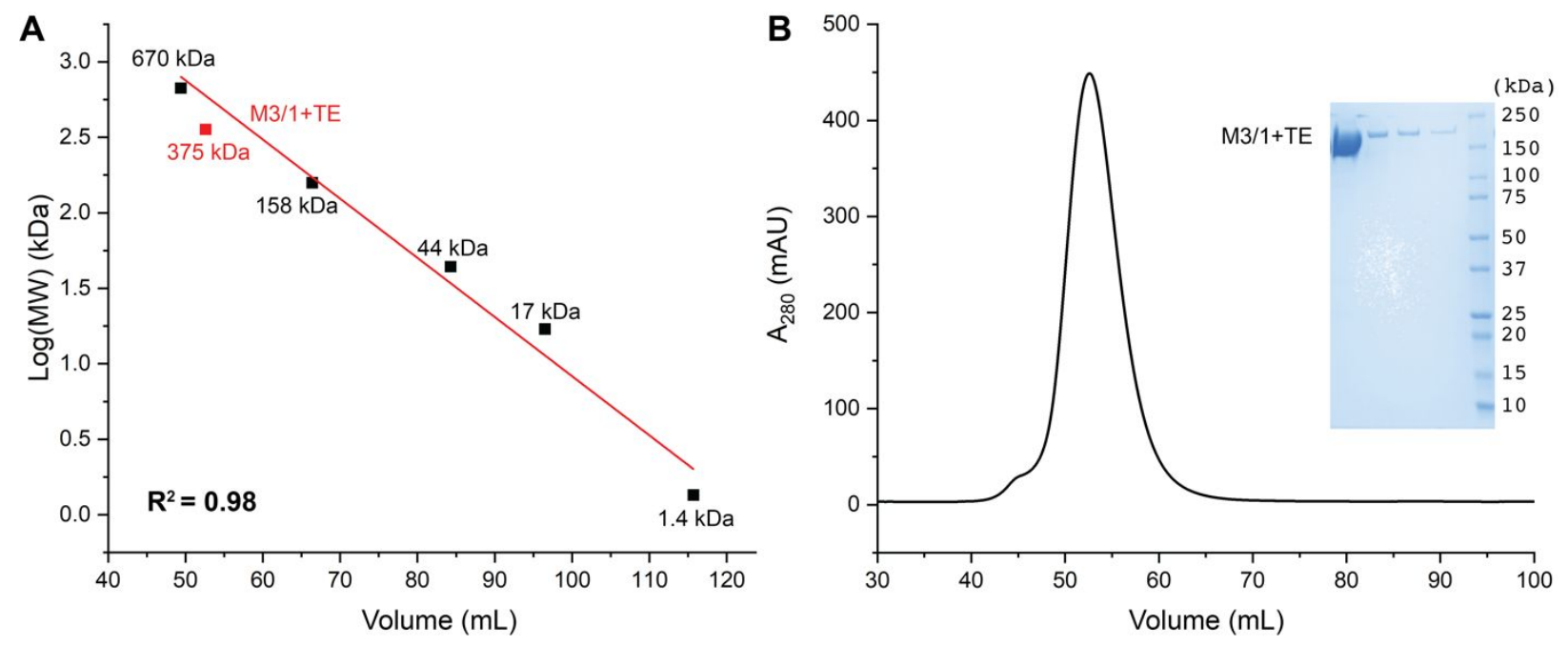

Figure S7: Size-exclusion chromatography (SEC) analysis of hybrid DEBS module M3/1+TE. (A) The size (logarithmic) and retention volume of M3/1+TE relative to a standard-curve generated from five commercial standards (Supporting Methods). (B) A SEC chromatogram of M3/1+TE and its analysis by SDS-PAGE. 
A bimodular DEBS
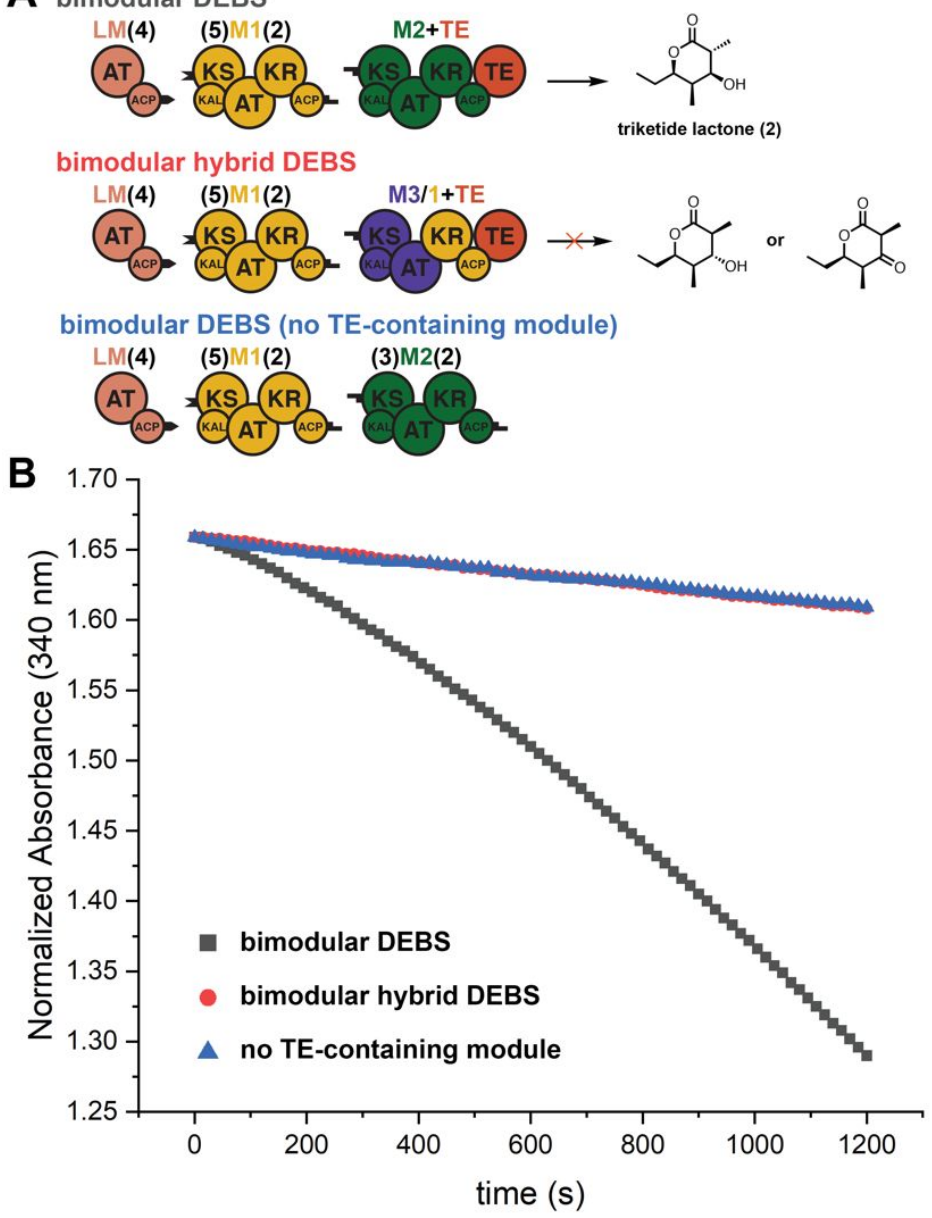

Figure S8: (A) Reconstituted bimodular DEBS (black), bimodular hybrid DEBS (red), and bimodular DEBS lacking a TE domain (blue). (B) NADPH depletion over time for the reconstituted reactions in panel A. See Supporting Methods for reaction details. 


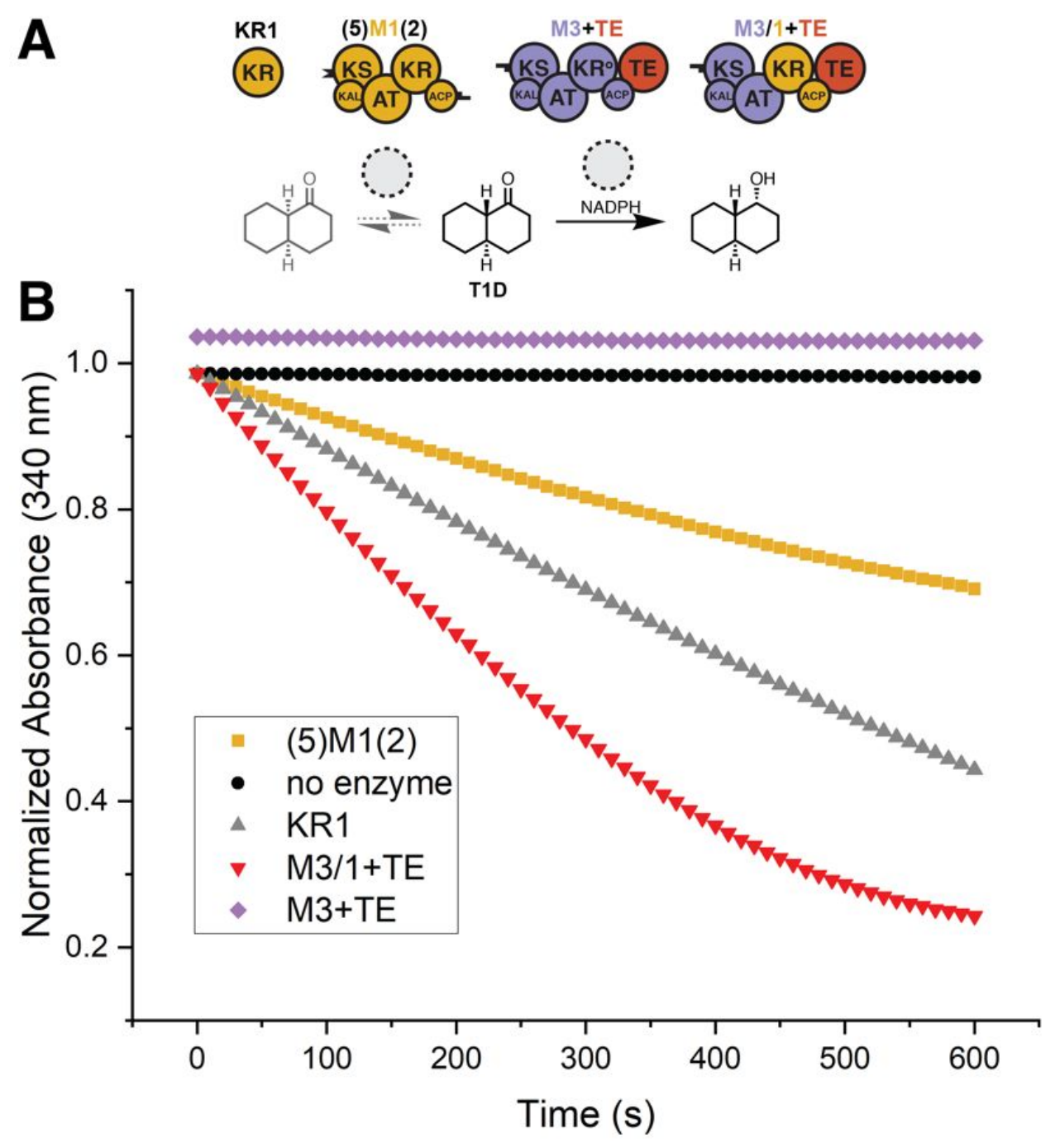

Figure S9: (A) Reduction of T1D by KR1, M3/1+TE, M3+TE, or (5)M1(2). (B) By monitoring NADPH consumption via absorbance at $340 \mathrm{~nm}, \mathrm{M} 3 / 1+\mathrm{TE}$ mediated reduction of T1D is demonstrated (red triangles). As expected, no enzyme-dependent oxidation of NADPH was observed in reactions containing the redox-inactive KR3 of M3+TE (purple triangles). KR1 also reduces T1D in its natural, moduleembedded context [i.e., (5)M1(2), yellow squares]. Note that KR1 and M3/1+TE were SEC-purified whereas the other proteins were only purified up to the anion-exchange purification step, perhaps partially explaining the relative activity differences (Supporting Methods). A reaction lacking enzyme was included as a negative control (black circles). 
A

$\longrightarrow$ Fab
$M 3 / 1+T E$
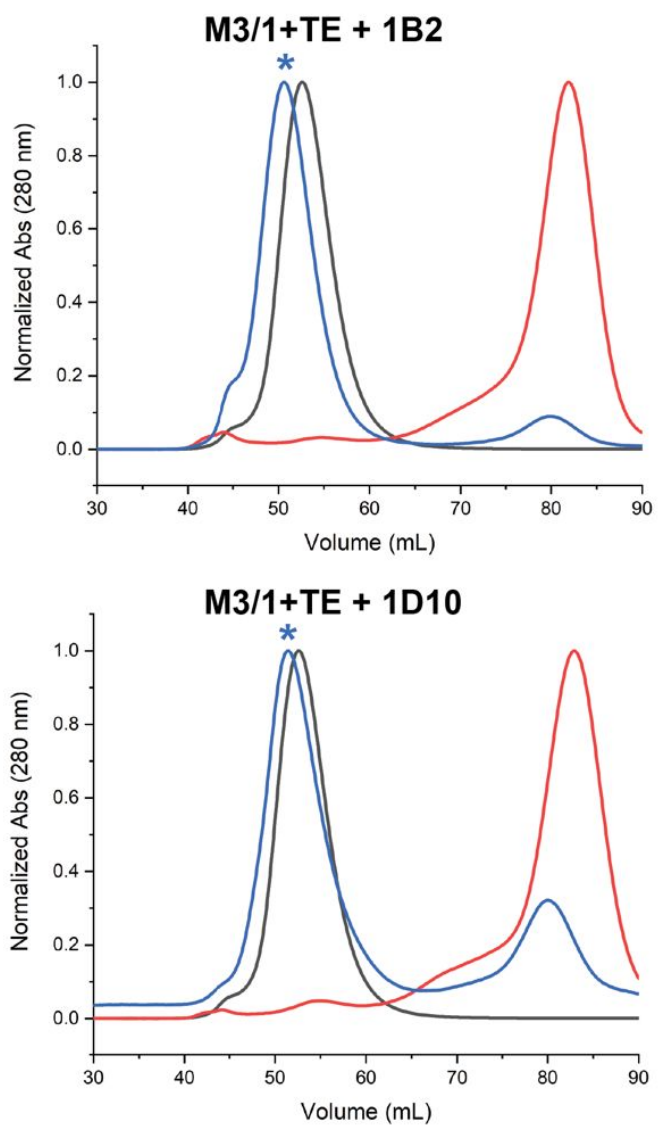

B

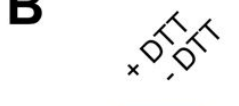

( $\mathrm{kDa}$ )
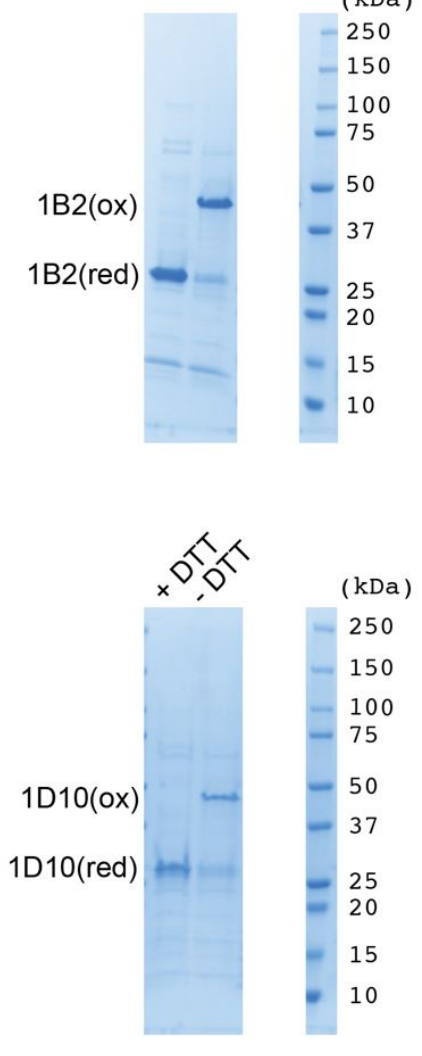

C
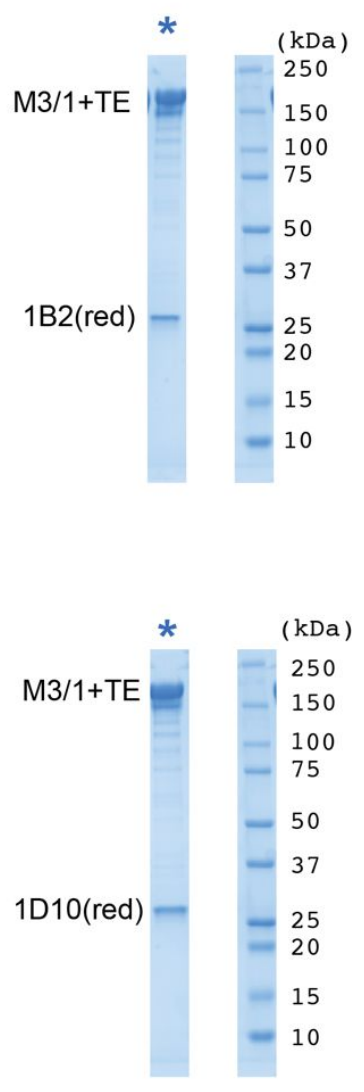

Figure S10: SEC/SDS-PAGE analysis of M3/1+TE $+\mathrm{F}_{\mathrm{ab}} \mathrm{s} 1 \mathrm{~B} 2$ and 1D10. (A) SEC chromatograms of $\mathrm{M} 3 / 1+\mathrm{TE}+\mathrm{F}_{\mathrm{ab}} \mathrm{S} 1 \mathrm{~B} 2$ and 1D10 (Supporting Methods). (B) SDS-PAGE analysis of Ni-NTA affinitypurified $\mathrm{F}_{\mathrm{ab}} \mathrm{S} 1 \mathrm{~B} 2$ and 1D10. Prior to gel electrophoresis, the samples were heat denatured at $95{ }^{\circ} \mathrm{C}$ for 5 min in Laemmli Buffer (Bio-Rad, catalog \# 1610737) containing $3 \mathrm{mM}$ DTT (+DTT) or lacking any reducing agent (-DTT) to support the presence of disulfide-linked $\mathrm{F}_{\mathrm{ab}}$ heterodimers. (C) Fractions corresponding to the $\mathrm{F}_{\mathrm{ab}} \mathrm{M} 3 / 1+\mathrm{TE}$ complexes (peaks labeled with blue asterisks in panel A) were concentrated to $\geq 10 \mathrm{mg} / \mathrm{mL}$ using an Amicon Ultra Centrifugal Filter (Millipore Sigma) for SEC-SAXS and SDS-PAGE analysis. 


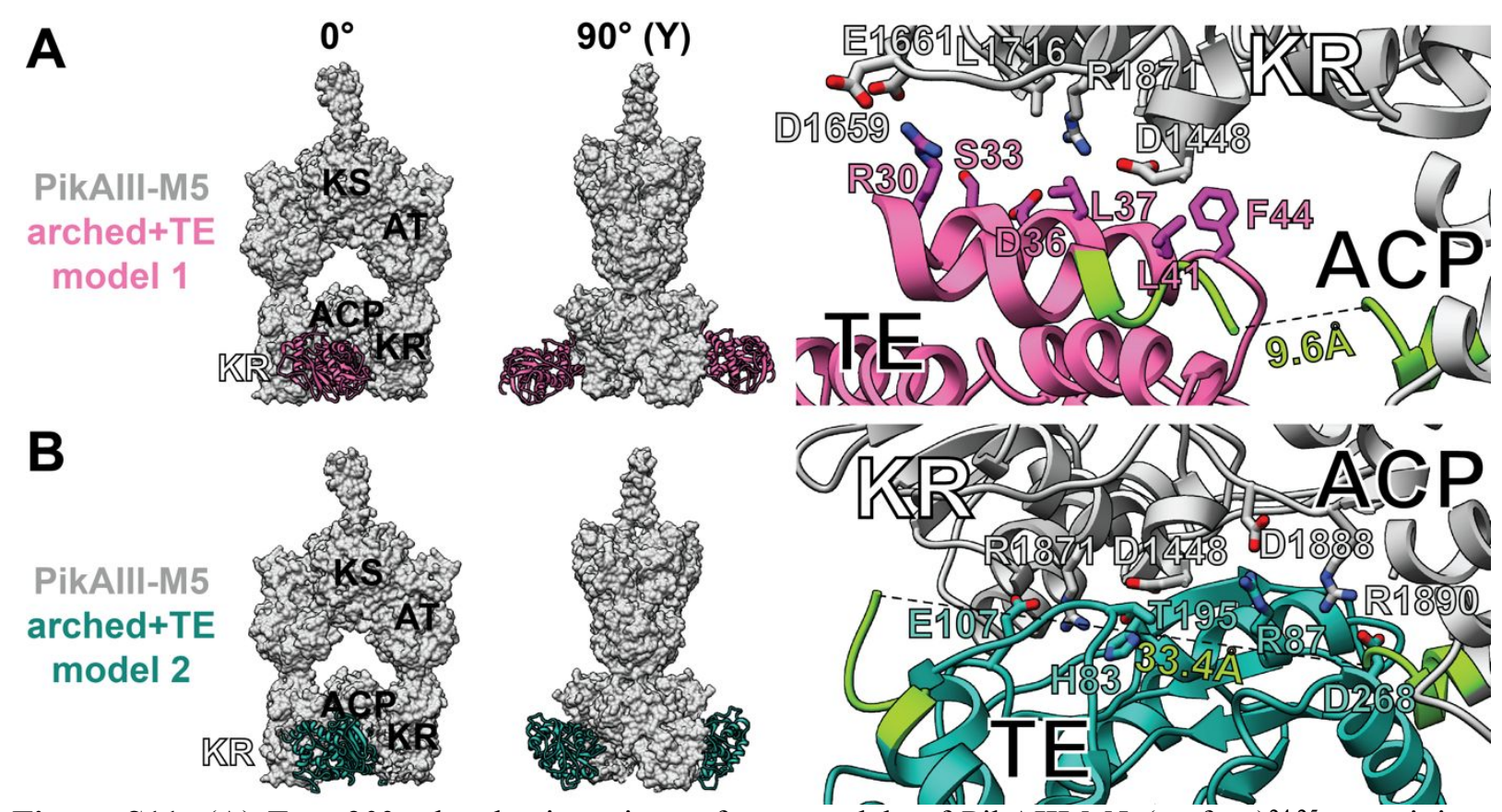

Figure S11: (A) Two $90^{\circ}$-related orientations of two models of PikAIII-M5 (surface) ${ }^{24,25}$ containing a thioesterase (TE) domain (ribbons). TE coordinates are derived from PDB 1KEZ ${ }^{27}$. One model "arched+TE model 1" in magenta contains a manually placed TE and another "arched+TE model 2" in teal contains a docked TE using PatchDock ${ }^{28}$. (B) A closer view of the TE/KR1-ACP1 interfaces. TE residue numbering is consistent with PDB 1KEZ. Note the separation between the C-terminus of ACP1 and N-terminus of TE (highlighted in bright green) is compatible with the native 8-residue spacer in arched+TE model 1 . The two TE positions also pose no conflict with 1D10 and 2G10 binding (Supporting Fig. S6 and Table S3). 


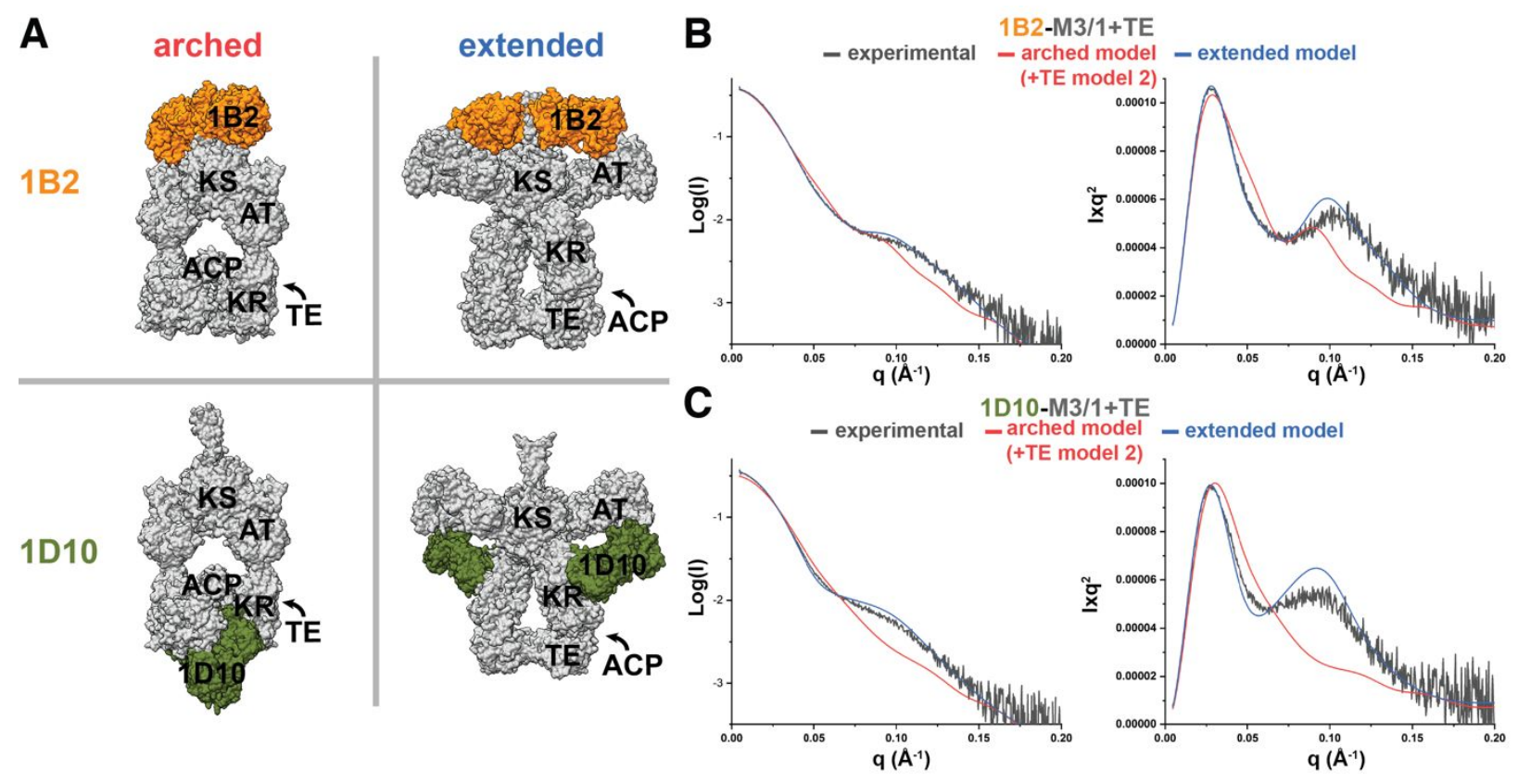

Figure S12: SEC-SAXS analysis of $\mathrm{F}_{\mathrm{ab}}$-bound M3/1+TE. (A) Models of the arched (red) ${ }^{24,25}$ and extended (blue) $^{26}$ models of an assembly-line PKS module bound to $\mathrm{F}_{\mathrm{ab}} \mathrm{S} 1 \mathrm{~B} 2$ (orange) ${ }^{15}$ and 1D10 (green). The arched models reflect the arched+TE model 2 (Supporting Fig. S11). (B,C) Log(I) vs. q (left) and Kratky (right) plots of the 1B2-M3/1+TE (panel B) and 1D10-M3/1+TE (panel C) experimental SEC-SAXS data (black traces) superposed with CRYSOL-generated predicted curves for the arched (red traces) and extended models (blue traces) shown in panel A (Supporting Tables S2-S3) ${ }^{20}$. 


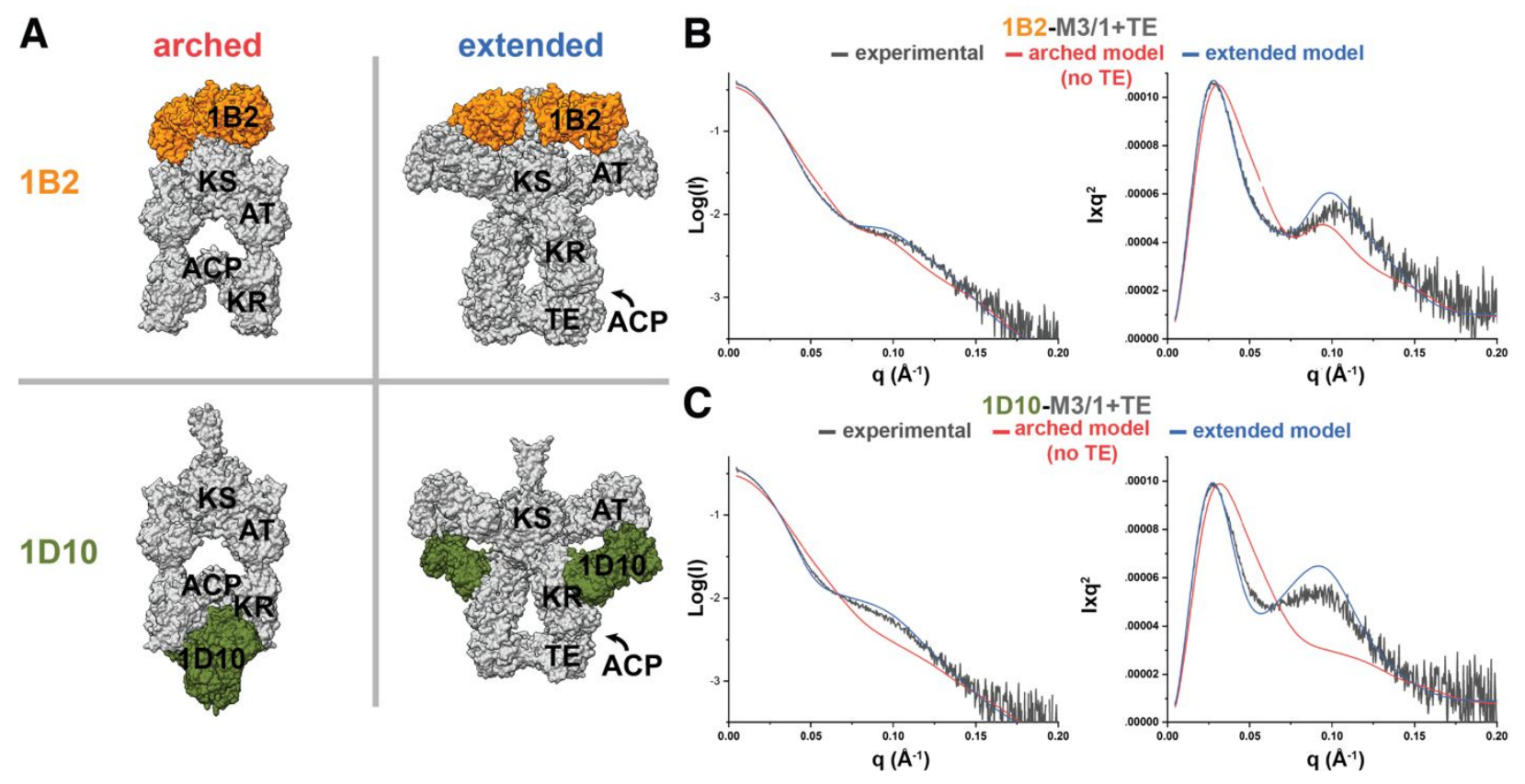

Figure S13: SEC-SAXS analysis of $\mathrm{F}_{\mathrm{ab}}$-bound M3/1+TE. (A) Models of the arched (red) ${ }^{24,25}$ and extended (blue $^{26}$ models of an assembly-line PKS module bound to $\mathrm{F}_{\mathrm{ab}} \mathrm{S} 1 \mathrm{~B} 2$ (orange) ${ }^{15}$ and 1D10 (green). The arched models reflect the arched model lacking a TE domain (Supporting Fig. S11). (B,C) Log(I) vs. q (left) and Kratky (right) plots of the 1B2-M3/1+TE (panel B) and 1D10-M3/1+TE (panel C) experimental SEC-SAXS data (black traces) superposed with CRYSOL-generated predicted curves for the arched (red traces) and extended models (blue traces) shown in panel A (Supporting Tables S2-S3) ${ }^{20}$. 


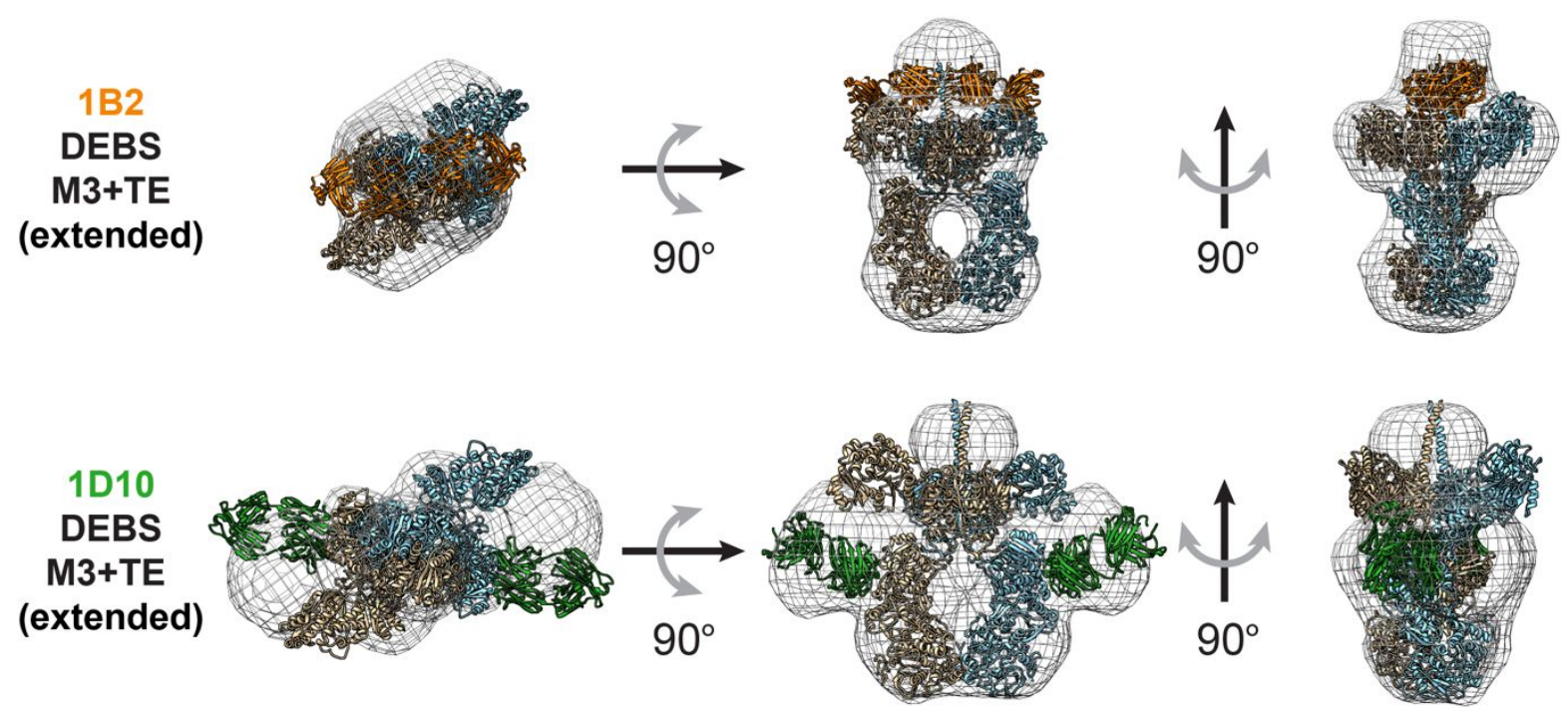

Figure S14: Selected $a b$ initio SAXS envelopes calculated from the 1B2-M3/1+TE and 1D10-M3/1+TE SECSAXS data. The program DAMMIF ${ }^{21}$ was employed using the experimental scattering data shown in Figures 5B and 5C (Supporting Methods). The extended models of 1B2- and 1D10-bound DEBS M3+TE were used to manually fit the selected envelopes ${ }^{15,26}$. Three rotationally related orientations are shown for each model-fitted envelope. 
Table S1: Crystallographic data collection and refinement statistics.

\begin{tabular}{|c|c|c|}
\hline & KR1-1D10 (PDB 6WH9) & KR1-2G10 (PDB 6W7S) \\
\hline \multicolumn{3}{|l|}{ Data collection } \\
\hline Space group & $C 121$ & $C 222_{1}$ \\
\hline \multicolumn{3}{|l|}{ Cell dimensions } \\
\hline$a, b, c(\AA)$ & $186.0,114.8,186.1$ & $80.1,129.5,208.8$ \\
\hline$\alpha, \beta, \gamma\left(^{\circ}\right)$ & $90.0,96.5,90.0$ & $90.0,90.0,90.0$ \\
\hline Resolution $(\AA)^{1}$ & $92.60-2.75(2.94-2.75)$ & $39.36-2.25(2.32-2.25)$ \\
\hline $\mathrm{R}_{\text {merge }} 1$ & $0.071(0.994)$ & $0.261(2.006)$ \\
\hline $\mathrm{R}_{\text {meas }} 1$ & $0.074(1.032)$ & $0.281(2.082)$ \\
\hline $\mathrm{R}_{\mathrm{pim}}{ }^{1}$ & $0.020(0.277)$ & $0.075(0.554)$ \\
\hline$I / \sigma I^{I}$ & $23.4(2.4)$ & $8.7(1.6)$ \\
\hline Completeness $(\%)^{1}$ & $97.6(99.9)$ & $99.9(99.2)$ \\
\hline Redundancy ${ }^{1}$ & $14.0(13.8)$ & $13.7(13.9)$ \\
\hline $\mathrm{CC}_{1 / 2}$ & $0.999(0.913)$ & $0.995(0.681)$ \\
\hline \multicolumn{3}{|l|}{ Refinement } \\
\hline Resolution $(\AA)$ & $39.59-2.75$ & $39.36-2.25$ \\
\hline No. reflections & 100,798 & 51,841 \\
\hline $\mathrm{R}_{\mathrm{work}} / \mathrm{R}_{\text {free }}{ }^{2}$ & $23.0 / 26.4$ & $17.9 / 23.2$ \\
\hline \multicolumn{3}{|l|}{ No. atoms } \\
\hline Total & 19,435 & 7,113 \\
\hline Protein & 19,254 & 6,674 \\
\hline Ligand/ion & 35 & 13 \\
\hline Water & 146 & 426 \\
\hline \multicolumn{3}{|l|}{ B-factors } \\
\hline Total & 107.3 & 36.5 \\
\hline Protein & 107.6 & 36.4 \\
\hline Ligand/ion & 113.5 & 39.0 \\
\hline Water & 70.8 & 37.7 \\
\hline \multicolumn{3}{|l|}{ R.m.s. deviations } \\
\hline Bond lengths $(\AA)$ & 0.017 & 0.007 \\
\hline Bond angles $\left({ }^{\circ}\right)$ & 1.96 & 0.89 \\
\hline Clashscore & 11.9 & 4.2 \\
\hline
\end{tabular}

1. Highest resolution shell is shown in parentheses.

2. R-work $=\Sigma\left(\left|\mathrm{F}_{\text {obs }}\right|-\mathrm{k} \mid \mathrm{F}_{\text {calc }}\right) / \Sigma\left|\mathrm{F}_{\text {obs }}\right|$ and $\mathrm{R}$-free is the $\mathrm{R}$ value for a test set of reflections consisting of a random $5 \%$ of the diffraction data not used in refinement. 
Table S2: SEC-SAXS data collection and processing parameters.

\begin{tabular}{lcc}
\hline Sample & 1B2-M3/1+TE & 1D10-M3/1+TE \\
\hline Data collection parameters & & \\
\hline Instrument & SSRL BL4-2 & SSRL BL4-2 \\
Defining slits size $(\mathrm{H} \mathrm{mm} \mathrm{x} \mathrm{V} \mathrm{mm)}$ & $0.25 \times 0.25$ & $0.25 \times 0.25$ \\
Detector distance $(\mathrm{m})$ & 2.5 & 2.5 \\
Detector & Pilatus3 X 1M & Pilatus3 X 1M \\
Beam energy $(\mathrm{keV})$ & 11 & 11 \\
q range $\left(\AA^{-1}\right)$ & $0.0046-0.356$ & $0.0046-0.356$ \\
Exposure time/frame $(\mathrm{s})$ & 1 & 1 \\
Frames per data set & 550 & 550 \\
Temperature $(\mathrm{K})$ & 297.9 & 297.9 \\
\hline SEC parameters & & Superose 6 \\
\hline SEC column & Superose 6 & $0.55-1.36$ \\
Amount loaded $(\mathrm{nmol})$ & $0.71-1.77$ & 0.04 \\
HPLC flow rate $(\mathrm{mL} / \mathrm{min})$ & 0.04 & \\
\hline Structural parameters & & $0.36 \pm 0.0098$ \\
\hline$I(\mathrm{o})$ from Guinier & $0.39 \pm 0.001$ & $64.06 \pm 0.25$ \\
$R_{\mathrm{g}}(\AA)$ & $63.45 \pm 0.25$ & 0.36 \\
$I(\mathrm{o})$ from $\mathrm{P}(r)$ & 0.39 & 64.46 \\
$R_{\mathrm{g}}(\AA)$ from $\mathrm{P}(r)$ & 64.60 & 218.55 \\
$D_{\text {max }}(\AA)$ from $\mathrm{P}(r)$ & 217.52 & 965,484 \\
Porod volume estimate $\left(\AA^{3}\right)$ & $1,068,910$ & \\
\hline Software employed & & SasTool \\
\hline Primary data reduction & SasTool & PRIMUS \\
Data processing & PRIMUS & \\
& & \\
\hline & & \\
\hline
\end{tabular}


Table S3: Summary of SAXS curve fitting data.

\begin{tabular}{lcccc}
\hline Experimental data & \multicolumn{4}{c}{ 1B2-M3/1+TE } \\
\hline Models & Arched+TE 1 & Arched+TE 2 & Arched (no TE) & Extended \\
Software employed & CRYSOL & CRYSOL & CRYSOL & CRYSOL \\
Predicted $R_{\mathrm{g}}(\AA)$ & 66.55 & 65.49 & 61.94 & 63.12 \\
Predicted $D_{\max }(\AA)$ & 221.2 & 207.9 & 197.6 & 206.3 \\
q range $\left(\AA^{-1}\right)$ & $0.005-0.355$ & $0.005-0.355$ & $0.005-0.355$ & $0.005-0.355$ \\
Chi-squared & 8.49 & 12.64 & 27.08 & 1.93 \\
\hline Experimental data & \multicolumn{4}{c}{$\mathbf{1 D 1 0 - M 3 / 1 + T E}$} \\
\hline Models & Arched+TE 1 & Arched+TE 2 & Arched (no TE) & Extended \\
Software employed & CRYSOL & CRYSOL & CRYSOL & CRYSOL \\
Predicted $R_{\mathrm{g}}(\AA)$ & 61.63 & 60.73 & 60.37 & 63.15 \\
Predicted $D_{\max }(\AA)$ & 238.2 & 239.2 & 239.2 & 250.1 \\
q range $\left(\AA^{-1}\right)$ & $0.005-0.355$ & $0.005-0.355$ & $0.005-0.355$ & $0.005-0.355$ \\
Chi-squared & 18.14 & 30.42 & 49.47 & 5.29
\end{tabular}


Table S4: Summary of SAXS curve fitting data featuring models with single $\mathrm{F}_{\mathrm{ab}}$ heterodimers bound. The model coordinates used in this analysis are identical to those shown in Figure 5, with the exception of having one of the two, symmetry-related $\mathrm{F}_{\mathrm{ab}}$ heterodimers removed.

\begin{tabular}{lcc}
\hline Experimental data & \multicolumn{2}{c}{ 1B2-M3/1+TE } \\
\hline \multirow{2}{*}{$\left(\right.$ single $\left.\mathrm{F}_{\mathrm{ab}}\right)$} \\
Models & Arched+TE 1 & Extended \\
Software employed & CRYSOL & CRYSOL \\
Predicted $R_{\mathrm{g}}(\AA)$ & 63.16 & 62.64 \\
Predicted $D_{\max }(\AA)$ & 205.6 & 208.8 \\
q range $\left(\AA^{-1}\right)$ & $0.005-0.355$ & $0.005-0.355$ \\
Chi-squared & 13.34 & 4.20 \\
\hline Experimental data & \multicolumn{2}{c}{$\mathbf{1 D 1 0 - M 3 / 1 + T E}$} \\
\hline \multicolumn{2}{c}{$\left(\right.$ single $\left.\mathrm{F}_{\mathrm{ab}}\right)$} \\
Models & Arched+TE 1 & Extended \\
Software employed & CRYSOL & CRYSOL \\
Predicted $R_{\mathrm{g}}(\AA)$ & 60.82 & 62.25 \\
Predicted $D_{\max }(\AA)$ & 235.0 & 206.4 \\
q range $\left(\AA^{-1}\right)$ & $0.005-0.355$ & $0.005-0.355$ \\
Chi-squared & 11.91 & 3.29
\end{tabular}


Table S5: Plasmids used in this study (Kan = kanamycin; Carb = carbenicillin; Amp = ampicillin).

\begin{tabular}{cccc}
\hline Plasmid Name & Encoded Protein & Antibiotic Resistance & Reference \\
\hline pBL12 & LDD(4) & Kan & Lowry et al. $^{29}$ \\
pBL13 & $(5) M 1(2)$ & Carb/Amp & Lowry et al. $^{29}$ \\
pBL36 & $(3)$ M2(2) & Carb/Amp & Lowry et al. $^{29}$ \\
pBL16 & 3)M2+TE & Carb/Amp & Lowry et al. $^{29}$ \\
pLKC50 & M3 & Carb/Amp & Edwards et al. $^{26}$ \\
pRSG34 & M3+TE & Carb/Amp & Gokhale et al. $^{30}$ \\
PrpE-pET28 & PrpE & Kan & Lowry et al. $^{4}$ \\
*SCME-pET28 & SCME & Kan & Hughes et al. \\
*MatB-pET28 & MatB & Kan & Hughes et al. ${ }^{5}$ Walker et al. ${ }^{6}$ \\
pAYC59 & KR1 & Kan & Chen et al. ${ }^{31}$ \\
n/a & 1D10-flag & Carb/Amp & Kim et al. ${ }^{32}$ \\
n/a & 2G10-myc & Carb/Amp & Kim et al. ${ }^{32}$ \\
n/a & 1B2-flag & Carb/Amp & Kim et al. ${ }^{32}$ \\
pTED23 & M3/1+TE & Carb/Amp & this study \\
\hline
\end{tabular}

*A gift from Prof. Michelle Chang's lab (University of California, Berkeley) 
Table S6: Oligonucleotides used in this study. See Supporting Methods for amplicon details and Table S5 for template references.

\begin{tabular}{cccc}
\hline Name & Sequence $\left(\mathbf{5}^{\prime} \rightarrow \mathbf{3}^{\prime}\right)$ & PCR amplicon & PCR template \\
\hline Amp $^{\mathrm{R}}$ F & GACAACGATCGAGGACCGAAGGAG & 1 & pRSG34 \\
pTED23_1 & GTAGGCCAGCTCGTCGGAGG & 1 & pRSG34 \\
pTED23_2 & GACGAGCTGGCCTACCGCATCGAGTGGCGGC & 2 & pBL13 \\
pTED23_3 & GGCGGGAGTCCCGTGCCGATTCGGCGGCCA & 2 & pBL13 \\
pTED23_4 & AGCGGGACTCCCGCCC & 3 & pRSG34 \\
Amp $^{\text {R__R }}$ & CTCCTTCGGTCCTCCGATCGTTGTC & 3 & pRSG34
\end{tabular}




\section{Supporting References}

(1) Gibson, D. G.; Benders, G. A; Andrews-Pfannkoch, C.; Denisova, E. A; Baden-Tillson, H.; Zaveri, J.; Stockwell, T. B.; Brownley, A.; Thomas, D. W.; Algire, M. A.; Merryman, C.; Young, L.; Noskov, V. N.; Glass, J. I.; Venter, J. C.; Hutchinson 3 ${ }^{\text {rd }}$, C. A.; Smith, H. O. Complete Chemical Synthesis, Assembly, and Cloning of a Mycoplasma Genitalium Genome. Science 2008, 319 (5867), 1215-1220.

(2) Gibson, D. G.; Young, L.; Chuang, R.-Y.; Venter, J. C.; Hutchinson $3^{\text {rd }}$, C. A.; Smith, H. O. Enzymatic Assembly of DNA Molecules up to Several Hundred Kilobases. Nat. Methods 2009, 6 (5), 343-345.

(3) Pfeifer, B. A.; Admiraal, S. J.; Gramajo, H.; Cane, D. E.; Khosla, C. Biosynthesis of Complex Polyketides in a Metabolically Engineered Strain of E. Coli. Science 2001, 291 (5509), 17901792.

(4) Lowry, B.; Li, X.; Robbins, T.; Cane, D. E.; Khosla, C. A Turnstile Mechanism for the Controlled Growth of Biosynthetic Intermediates on Assembly Line Polyketide Synthases. ACS Cent. Sci. 2016, 2 (1), 14-20.

(5) Hughes, A. J.; Keatinge-Clay, A. Enzymatic Extender Unit Generation for in Vitro Polyketide Synthase Reactions: Structural and Functional Showcasing of Streptomyces Coelicolor MatB. Chem. Biol. 2011, 18 (2), 165-176.

(6) Walker, M. C.; Thuronyi, B. W.; Charkoudian, L. K.; Lowry, B.; Khosla, C.; Chang, M. C. Y. Expanding the Fluorine Chemistry of Living Systems Using Engineered Polyketide Synthase Pathways. Science. 2013, 341 (6150), 1089 LP - 1094.

(7) Vonrhein, C.; Flensburg, C.; Keller, P.; Sharff, A.; Smart, O.; Paciorek, W.; Womack, T.; Bricogne, G. Data Processing and Analysis with the AutoPROC Toolbox. Acta Crystallogr. Sect. D Biol. Crystallogr. 2011, 67 (4), 293-302.

(8) McCoy, A. J.; Grosse-Kunstleve, R. W.; Adams, P. D.; Winn, M. D.; Storoni, L. C.; Read, R. J. Phaser Crystallographic Software. J. Appl. Crystallogr. 2007, 40 (4), 658-674.

(9) Waterhouse, A.; Bertoni, M.; Bienert, S.; Studer, G.; Tauriello, G.; Gumienny, R.; Heer, F. T.; de Beer, T. A. P.; Rempfer, C.; Bordoli, L.; Lepore, R.; Schwede, T. SWISS-MODEL: Homology Modelling of Protein Structures and Complexes. Nucleic Acids Res. 2018, 46 (May), gky427.

(10) Cowtan, K. The Buccaneer Software for Automated Model Building. 1. Tracing Protein Chains. Acta Crystallogr. Sect. D Biol. Crystallogr. 2006, 62 (9), 1002-1011.

(11) Terwilliger, T. C.; Grosse-Kunstleve, R. W.; Afonine, P. V.; Moriarty, N. W.; Zwart, P. H.; Hung, L. W.; Read, R. J.; Adams, P. D. Iterative Model Building, Structure Refinement and Density Modification with the PHENIX AutoBuild Wizard. Acta Crystallogr. Sect. D Biol. Crystallogr. 2007, 64 (1), 61-69.

(12) Afonine, P. V.; Grosse-Kunstleve, R. W.; Echols, N.; Headd, J. J.; Moriarty, N. W.; Mustyakimov, M.; Terwilliger, T. C.; Urzhumtsev, A.; Zwart, P. H.; Adams, P. D. Towards Automated Crystallographic Structure Refinement with Phenix.Refine. Acta Crystallogr. Sect. D Biol. Crystallogr. 2012, 68 (4), 352-367.

(13) Murshudov, G. N.; Skubák, P.; Lebedev, A. A.; Pannu, N. S.; Steiner, R. A.; Nicholls, R. A.; Winn, M. D.; Long, F.; Vagin, A. A. REFMAC5 for the Refinement of Macromolecular Crystal Structures. Acta Crystallogr. Sect. D Biol. Crystallogr. 2011, 67 (4), 355-367.

(14) Emsley, P.; Cowtan, K. Coot: Model-Building Tools for Molecular Graphics. Acta Crystallogr. Sect. D Biol. Crystallogr. 2004, 60 (12 I), 2126-2132.

(15) Li, X.; Sevillano, N.; La Greca, F.; Deis, L.; Liu, Y.-C.; Deller, M. C.; Mathews, I. I.; Matsui, T.; Cane, D. E.; Craik, C. S.; Khosla, C. Structure-Function Analysis of the Extended Conformation of a Polyketide Synthase Module. J. Am. Chem. Soc. 2018, 140 (21), 6518-6521.

(16) Bush, M.; Alhanshali, B. M.; Qian, S.; Stanley, C. B.; Heller, W. T.; Matsui, T.; Weiss, T. M.; Nicholl, I. D.; Walz, T.; Callaway, D. J. E.; Bu, Z. An Ensemble of Flexible Conformations Underlies Mechanotransduction by the Cadherin-Catenin Adhesion Complex. Proc. Natl. Acad. Sci. U. S. A. 2019, 116 (43), 21545-21555. 
(17) Petoukhov, M. V; Konarev, P. V; Kikhney, A. G.; Svergun, D. I. ATSAS 2.1 -- towards Automated and Web-Supported Small-Angle Scattering Data Analysis. J. Appl. Crystallogr. 2007, 40 (s1), s223--s228.

(18) Dreiss, C. A.; Jack, K. S.; Parker, A. P. On the Absolute Calibration of Bench-Top Small-Angle X-Ray Scattering Instruments: A Comparison of Different Standard Methods. J. Appl. Crystallogr. 2006, 39 (1), 32-38.

(19) Svergun, D. I. Determination of the Regularization Parameter in Indirect-Transform Methods Using Perceptual Criteria. J. Appl. Crystallogr. 1992, 25 (4), 495-503.

(20) Svergun, D.; Barberato, C.; Koch, M. H. J. CRYSOL -- a Program to Evaluate X-Ray Solution Scattering of Biological Macromolecules from Atomic Coordinates. J. Appl. Crystallogr. 1995, 28 (6), 768-773.

(21) Franke, D.; Svergun, D. I. DAMMIF, a Program for Rapid Ab-Initio Shape Determination in Small-Angle Scattering. J. Appl. Crystallogr. 2009, 42 (2), 342-346.

(22) Petoukhov, M. V; Svergun, D. I. Ambiguity Assessment of Small-Angle Scattering Curves from Monodisperse Systems. Acta Crystallogr. Sect. D 2015, 71 (5), 1051-1058.

(23) Keatinge-Clay, A. T.; Stroud, R. M. The Structure of a Ketoreductase Determines the Organization of the Beta-Carbon Processing Enzymes of Modular Polyketide Synthases. Structure 2006, 14 (4), 737-748.

(24) Dutta, S.; Whicher, J. R.; Hansen, D. A.; Hale, W. A.; Chemler, J. A.; Congdon, G. R.; Narayan, A. R. H.; Håkansson, K.; Sherman, D. H.; Smith, J. L.; Skiniotis, G. Structure of a Modular Polyketide Synthase. Nature 2014, 510, 512.

(25) Whicher, J. R.; Dutta, S.; Hansen, D. A.; Hale, W. A.; Chemler, J. A.; Dosey, A. M.; Narayan, A. R. H.; Håkansson, K.; Sherman, D. H.; Smith, J. L.; Skiniotis, G. Structural Rearrangements of a Polyketide Synthase Module during Its Catalytic Cycle. Nature 2014, 510, 560.

(26) Edwards, A. L.; Matsui, T.; Weiss, T. M.; Khosla, C. Architectures of Whole-Module and Bimodular Proteins from the 6-Deoxyerythronolide B Synthase. J. Mol. Biol. 2014, 426 (11), 2229-2245.

(27) Tsai, S. C.; Miercke, L. J.; Krucinski, J.; Gokhale, R.; Chen, J. C.; Foster, P. G.; Cane, D. E.; Khosla, C.; Stroud, R. M. Crystal Structure of the Macrocycle-Forming Thioesterase Domain of the Erythromycin Polyketide Synthase: Versatility from a Unique Substrate Channel. Proc. Natl. Acad. Sci. U. S. A. 2001, 98 (26), 14808-14813.

(28) Schneidman-Duhovny, D.; Inbar, Y.; Nussinov, R.; Wolfson, H. J. PatchDock and SymmDock: Servers for Rigid and Symmetric Docking. Nucleic Acids Res. 2005, 33 (Web Server issue), W363-7.

(29) Lowry, B.; Robbins, T.; Weng, C.-H.; O’Brien, R. V; Cane, D. E.; Khosla, C. In Vitro Reconstitution and Analysis of the 6-Deoxyerythronolide B Synthase. J. Am. Chem. Soc. 2013, 135 (45), 16809-16812.

(30) Gokhale, R. S.; Tsuji, S. Y.; Cane, D. E.; Khosla, C. Dissecting and Exploiting Intermodular Communication in Polyketide Synthases. Science 1999, 284 (5413), 482-485.

(31) Chen, A. Y.; Cane, D. E.; Khosla, C. Structure-Based Dissociation of a Type I Polyketide Synthase Module. Chem. Biol. 2007, 14 (7), 784-792.

(32) Kim, J.; Stroud, R. M.; Craik, C. S. Rapid Identification of Recombinant Fabs That Bind to Membrane Proteins. Methods 2011, 55 (4), 303-309. 